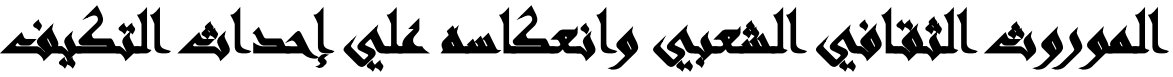

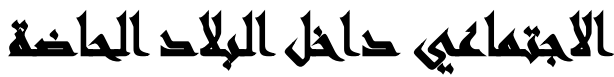

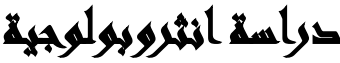

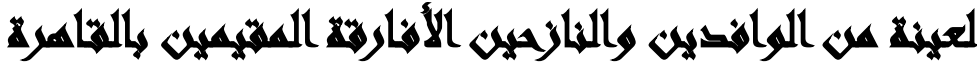

\section{[V]}

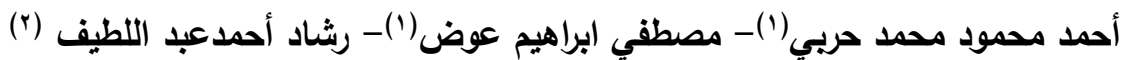

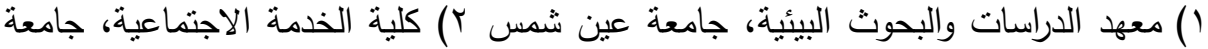
حلوان.

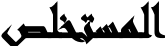

تهدف هذه الدراسة إلى التعرف الى أثنار التقاء ثقافتان الأفريقية ممثلة في الحكاية الثعبية

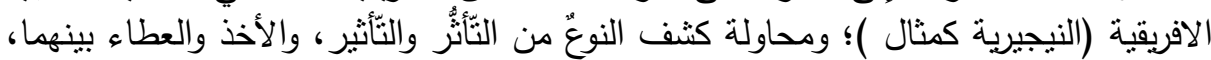

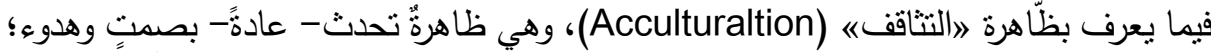

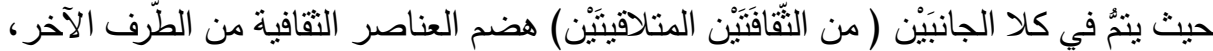

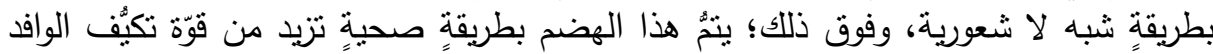

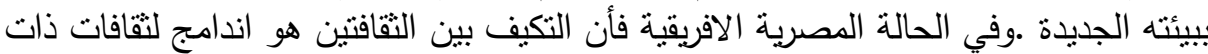
أصول مشتركة بعكس المقاومة التي يقوم بها التراث مقابل العولمة.

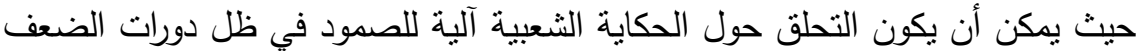

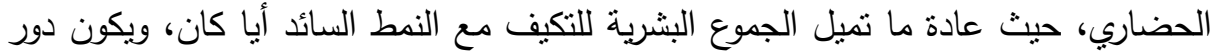

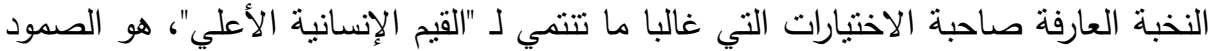

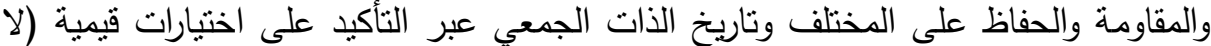
مادية) متخيلة وغائبة وموروثة.. تقف في وجه الانسحاق والاستلاب الحضاري الذئى الذي تمثله

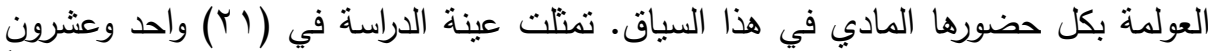
حالة، حيث أجريت المقابلات المتعمقة مع تلك الحالات للتأكد من بعض البئه البيانات، وتدعيماً لعمق الدراسة طبق الباحثون طريقة دراسة الحالة، إذ اختيرت واحد وعشرون حالة لدراستهم بشكل

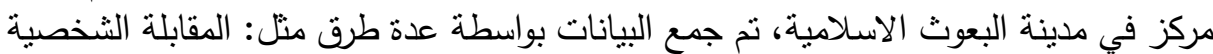

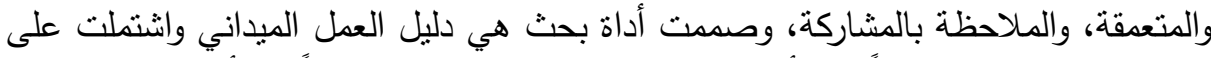

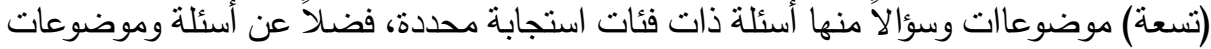
أخرى مفتوحة غير محددة الإجابة، يتعمق فيها عن طريق المقابلات فيما بعرف بالطريقة 


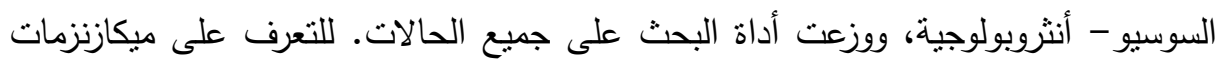

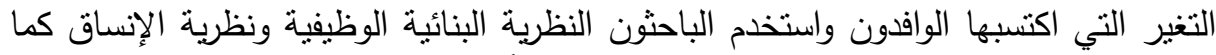

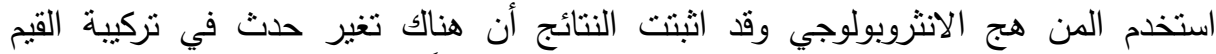

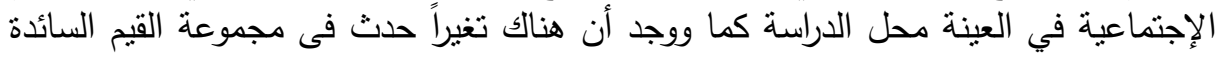

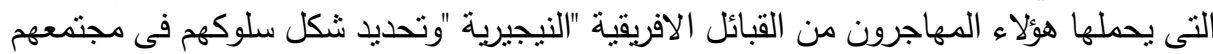
الجديد، حيث أتضح سيادة القيم الاقتصادية بينهم يليها القيم السياسية ثم الاجنماعية وأخيراً

وأوصت الدراسة الى ضرورة عدم التركيز كلية على الجانب الامني فقط في دراسة قضية

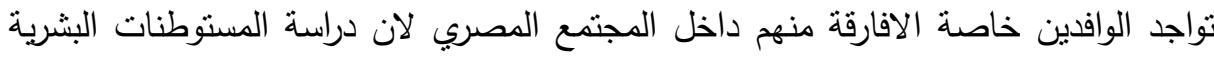

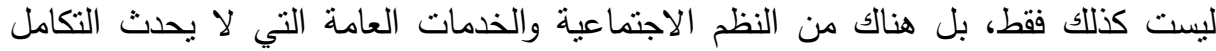

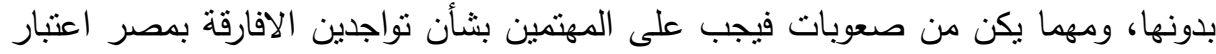

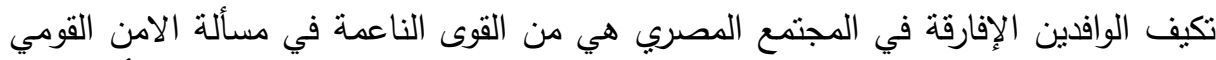
المصري والبعد الإفريقي وهي الطريقة المنلي لنتمية دور مصر في الفيقي الفيقيا بعتبارها بعدا أستراتيجيا للامن القومي. كما أوصت بضرورة الاهتمام بالعلاقات الأفريقية لأنها تساعد على الاستقرار وتحقق التعاون وبالتالي التكيف مع البيئة الجديدة.

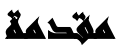

بعتبر مصطلح أو مفهوم الثقافة Culture من أكثر المصطلحات شيوعاً واستخداماً، وأنه

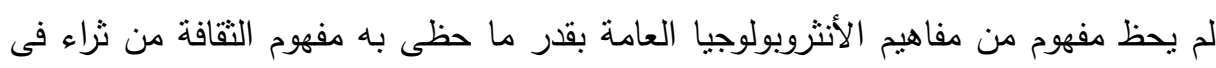

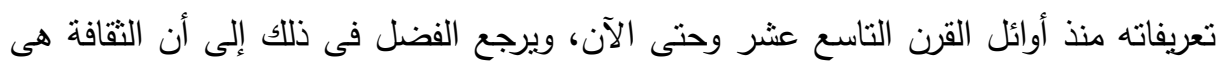

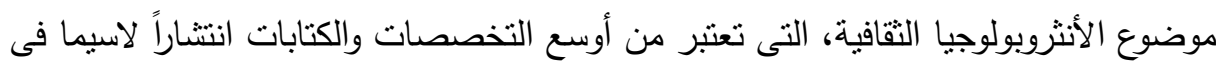

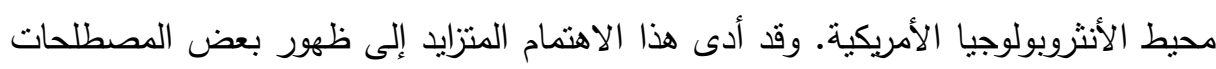

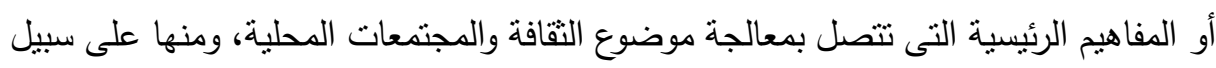

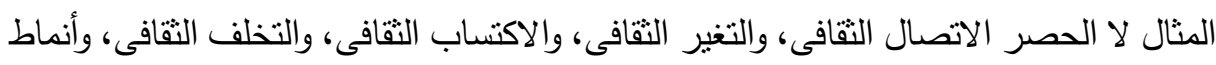
الثقافة، والثقافات الفرعية Sub- Cultures وغيرها.

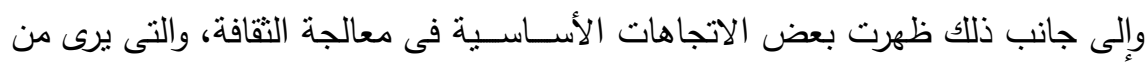

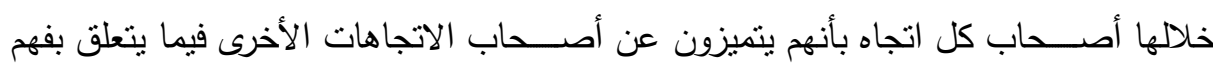

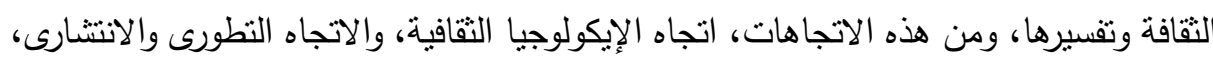

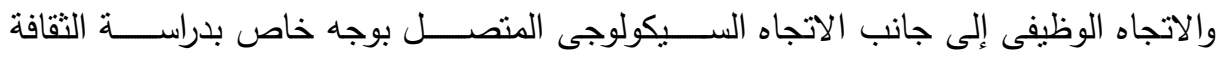


والثـصـية، أو بمعنى أخر دراسـة الثخصية فى الثقافة، ودراسـة الثقافة فى الثخصسية، إلى Tylor, E.B., Primitive ) غير ذلك من الاتجـاهـات والنزعـات المذهبيـة والمنهجيـة $\cdot(r \cdot) \cdot$ Culture

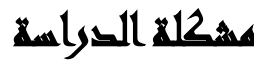

1-تطرقت العديد من الدراسات الى دراسة ظاهرة الهجرة الداخلية والخارجية، مثل دراسة علياء

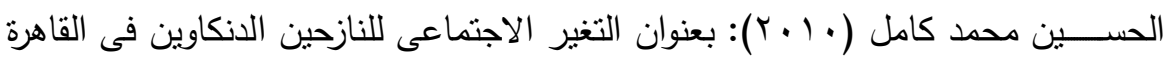

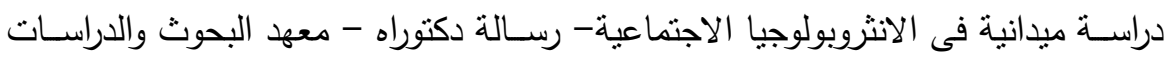

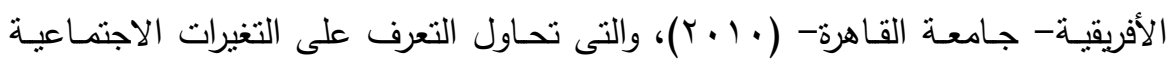

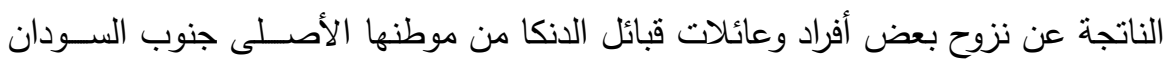
الي القاهرة نتيجة لعوامل عدة منها الحروب.وهدفت الى التعرف على التغيرات التى طرأت

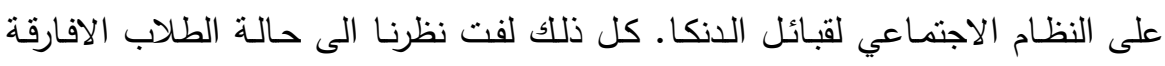

$$
\text { المقيمين في مصر ويشكلون حالة مشابهة. }
$$

كما قام رواد مدرسة شيكاغوا كذللك بدراسـة مشكلة تكيف المهاجرين بالمدن، والآثار التي هئي يمكن أن تخلفها الرواسب التقافية بالمجتمع الحضري. وعلاوة عن هذا بحثت في ظاهرة الهجرة

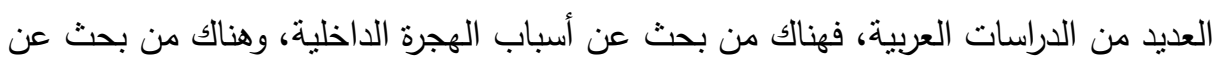

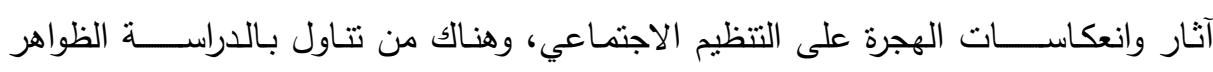

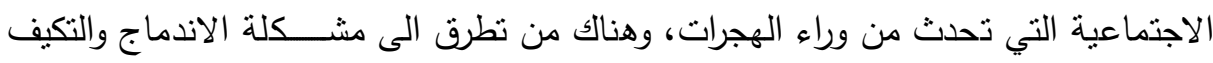

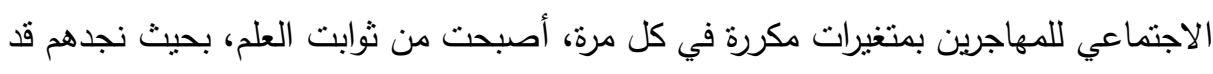

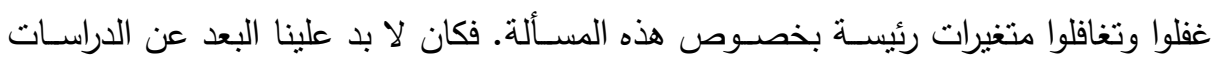

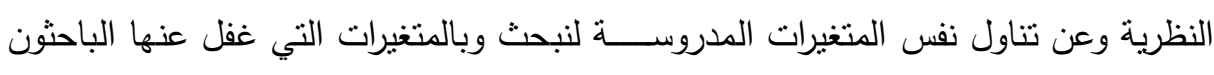

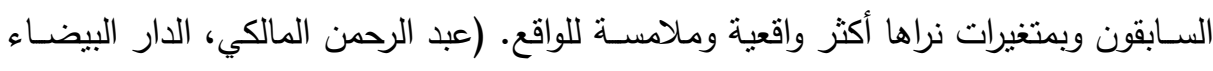


عن كيفية تشـكل واعادة تشـكل هوية الأفراد ذوبي الاصـــل الافريقية عند وفودهم على حلى

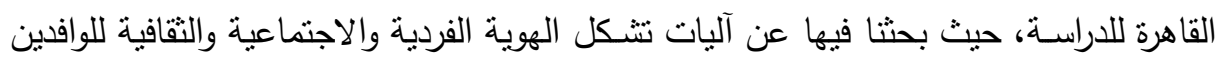
الجدد، أب البحث عن العوامل المؤثرة في تنكل هوية المهاجرين التي هي وليدة البيئة والمجال الاجتماعي التقليدي والحديث. وكنا قد انطلقنا من مجموعة من التسـاؤلات في أن المهاجر اما ها

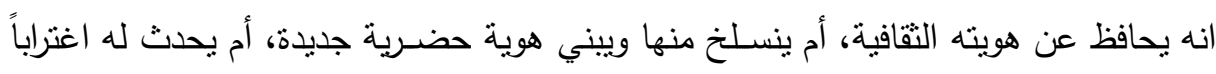
ثقافياً وبالتالي يسعى الى العزلة الاجتماعية والى العودة الى موطنه الأصلي.

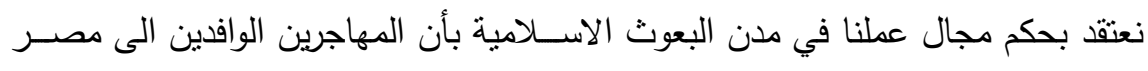

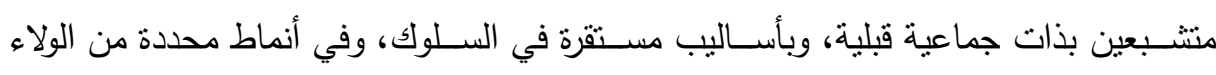

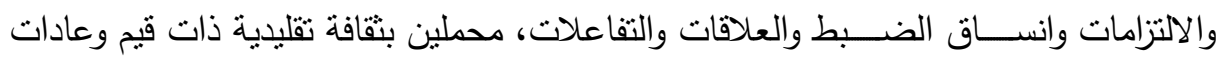
وتقاليد وأعراف وسلوكات وأفعال وعقليات وتصورات لذواتهم وللحياة، وهي ليست من السهل أن أن فئن

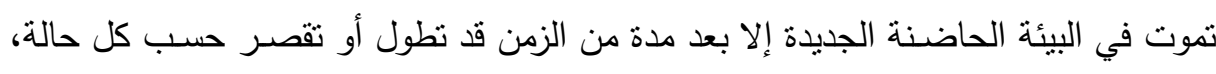

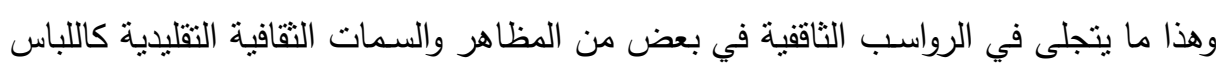

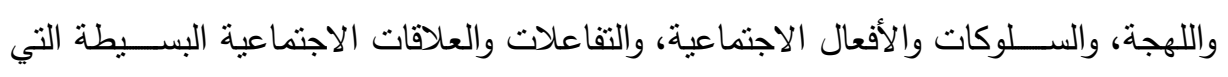
يحافظ عليهاً.

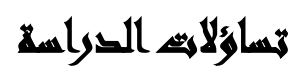

السؤال رئيسي هو هل اسلوب الحياة الثقافية للمهاجر ، واحتفاظه بموروثه التقافي هي التي

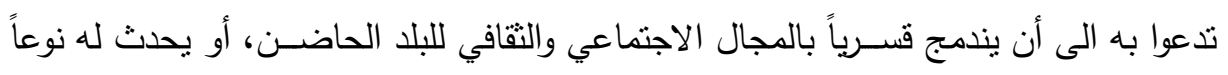

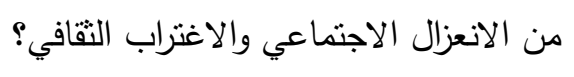

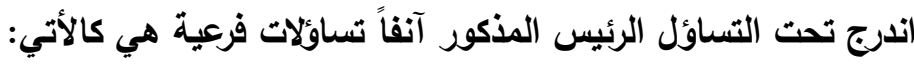

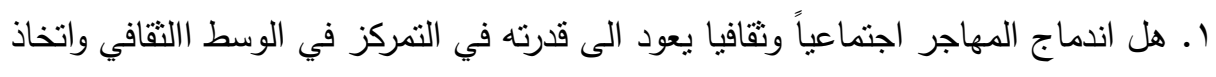

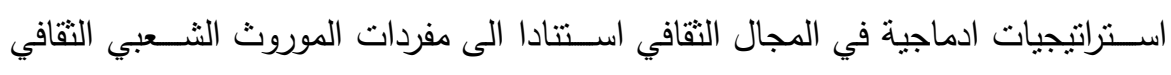

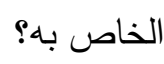

r. ما هي الآثار الاجتماعية والثقافية التى ترتبت على هذا الاندماج؟

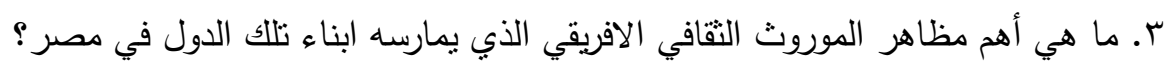


ـ ـ ماهي استراتيجيات التكيف الاجتماعي التي ينتهجها الوافدون للاندماج مع النقافة المصرية

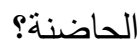

ه. هل تفاعلت الخصائص الاجتماعية والثقافية للأفارقة مع المجتمع المصري أم انعزلت عنه؟

\section{أهساهيم الصراسة}

\section{تهزف هذه الدراسة إلى التعرف على:}

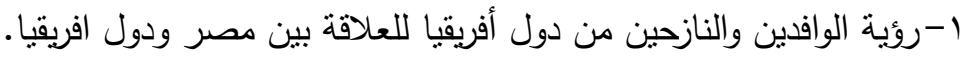

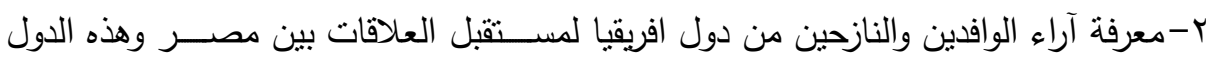

$$
\text { ودور التراث الثعبي في احداث التكيف الاجنماعي. }
$$

ب-رؤية الوافدين والنازحين من دول افريقيا لكيفية نوظيف الدكايات الثـــعبية للتغلب على الثى

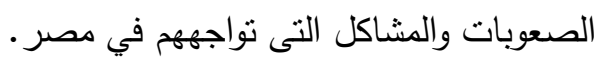

ع- التوصل لمقترحات حول أفضل السبل للاستفادة من الوافدين والنازحين من دول افريقيا فى دي حل المشاكل التى تواجه علاقات مصر بالدول الافريقية.

\section{أهمية الصوراسمة}

تتبع أهية هذه الدراسة من خلال مجموعة من المتغيرات والأحداث، التى يشهدها المجتمع

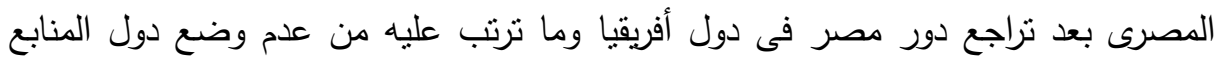

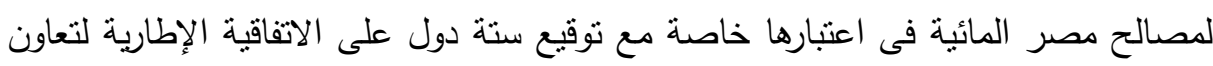
أعضاء مبادرة حوض النبلومن ثم وتتبع أهمية هذه الدراسة من عدة اعتبارات على اعلى النحو النالى: ا ـ الكثف عن العلاقة بين الموروث الثقافي الثعبي والمُحدِّدات الاجتماعيّة، والرّسمية، والدِّينية

$$
\text { في مُجنمع البحث. }
$$

r ـ يُعدُّ موضوع التراث الثعبي من الموضوعات الهامة في ميدان علم الانثروبولوجيا.

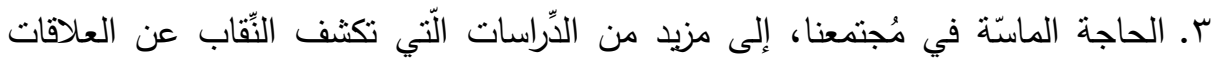
الاجتماعية المنبادلة بين الأفارقة المقيمين بمصر وأبناء المجنمع المنيد من المصري.

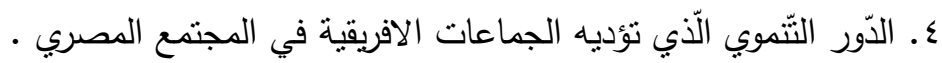


هـ أهية دراسة آراء الوافدين والنازحين من دول أفريقيا نحو المجتمع المصرى.

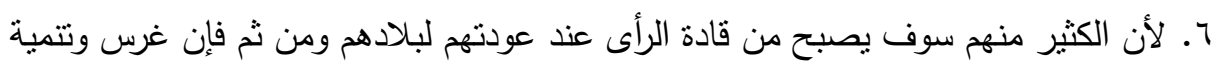
اتجاهاتهم الإيجابية نحو المجتمع المصرى يمكن أن تسهم فى خدمة مصر مسنقبلاً.

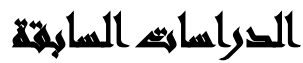

دراسات خاصة بلور مصر تجاه أفريقيا:

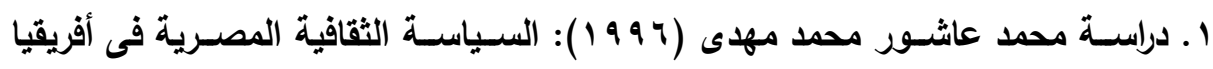
ضـــن أعمال ندوة مصـر وأفريقيا: مسـيرة العلاقات فى عالم متغير - التى عقدها معهد

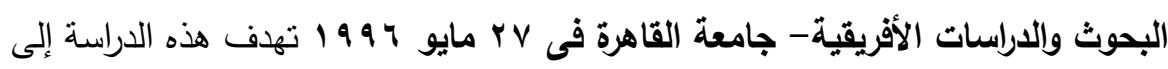
التعرف على المعوقات التى تواجه السياسة الثقافية المصرية فى أفريقيا.

توصلت الاراسة الى نتائج منها: • غياب خطة واضــــة للمصــالح والأهداف المبتغاة من العملية التعليمية للطلاب الأجانب والأفارقة منهم بصفة خاصة. • غياب التتسيق بين الأجهزة والمؤسسات المسئولة عن العلاقات الثقافية مع أفريقيا. • • • غلبة الاعتبارات السياسية الآنية فى رسم وتتفيذ السياسات. • عدم الحرص على متابعة السياسات المطبقة ودعم الروابط العقلية التى تم إيجادها.

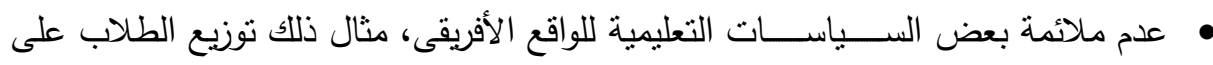
الكليات العملية والكليات النظرية (الثرعية).

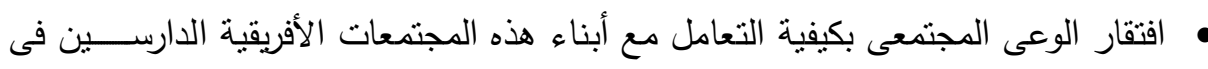
مصر على نحو ينعكس سلبياً على خبراتهم المكتسبة ومشاعرهم تجاه مصر وسياستها. تتقق هذه الدراسة مع الدراسة الحالية فى ما توصلت إليه من ملاحظات ونتائج.

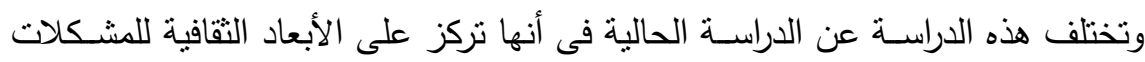
دون التطرق لباقى المشكلات. وقد اســتفاد الباحث من هذه الدراســـة فى التعرف على واقع وأحوال الســـاســـة الثقافية المصرية تجاه أفريقيا فى عقد التسعينيات من القرن العشرين. 
r . دراسـة على عبده محمود عبد الحميد (9 . . ب): دور الهيئة العامة للاستعلامات- كأداة

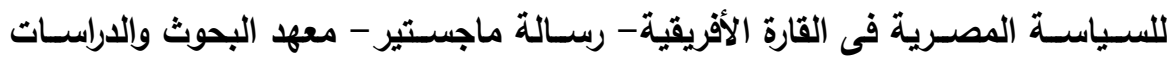
الأفريقية- جامعة القاهرة. تحاول هذه الدراسة التعرف على إحدى أدوات السياسة المصرية

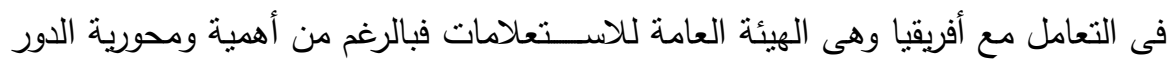

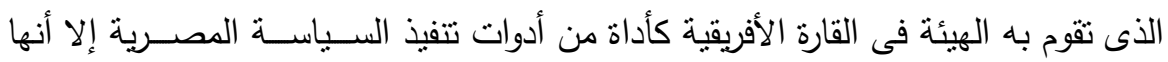

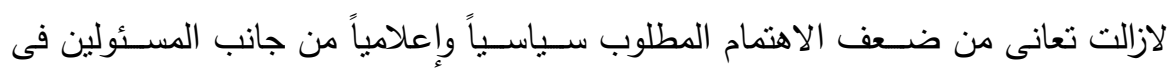
مصر وبالرغم من الجهود التى تبذلها المكانب الإعلامية التابعة للهيئة فى القارة بالإضـافة هنية

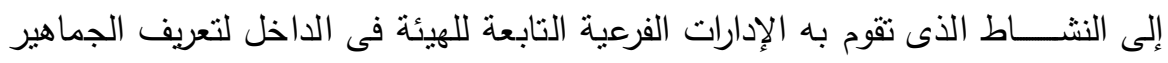

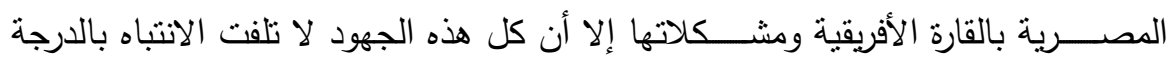

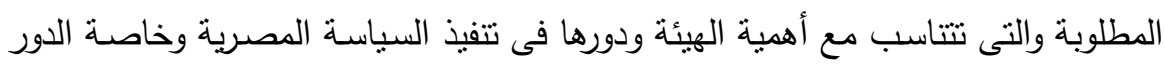
السباسى. وتوصلت لنتائج منها: • نجاح الهيئة نسبياً فى ظل إمكانياتها المحدودة فى القيام بدور فعال فى تقوية العلاقات

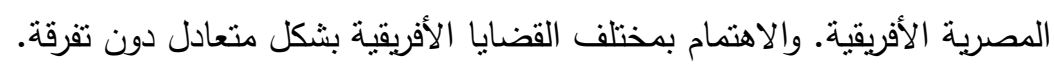
• عدم مسئولية الهيئة عن الكثير من أوجه القصور التى تظهر فى أدائها.

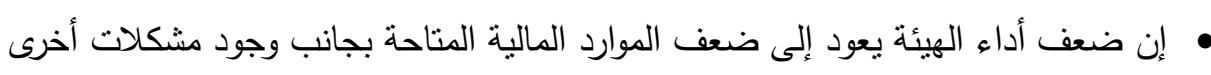
تحتاج للتنخل من جانب المسئولين لعلاج هذه المشكلات. تتفق هذه الدراسة مع الدراسة الحالية فى مجال الاهتمام حيث يتفقان على محاولة هدهات إيجاد وسائل لتدعيم السياسة المصرية فى أفريقيا وبحث معوقات تتفيذ هذئ هذه السياسة.

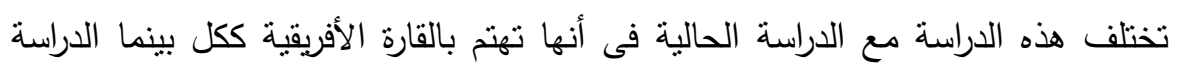
الحالية تهنم بدول حوض النيل فقط. • استفاد الباحث من هذه الدراسة فى التعرف على أحد أهم الأدوات التى يمكن استخدامها فى بـ تحسين صورة مصر لاى دول حوض النيل بما يسهم فى نتمية علاقات التعاون معها. 
r. دراسـة "هنرى، كليد Henery, \& Glyed" ( • 9 ( ): هدفت هذه الدراسـة للكثف عن مشكلات عدم تكيف الطلبة الأجانب [الوافيدن]، والذين يدرسون بجامعة ستانفورد بالولايات

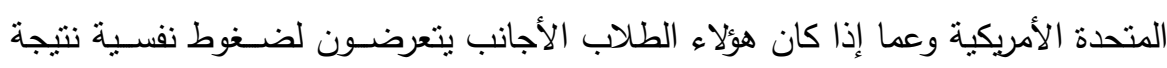
عدم تكبفهم مع البيئة الجديدة، وعما إذا كان ذللك له تأثثر على سلى سلوكياتهر.

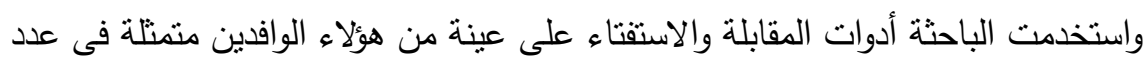
(9 ( §) طالب وافد يمنلون الجنسية المختلفة. وتوصلت هذه الدراسة إلى أن غالبية الششكلات التى يتعرض لها لهال الوافد نتمنل فى الآتى: • عدم تعاون الطلاب الآخرين معهم، وخاصة الجنسيات الأخرى. • • • عدم ضبط الوقت، وعدم تتاسب أسلوب الامتحانات مع قدراتهم. • عدم وجود علاقات شخصية ما بين الطلاب الوافدين والطلاب الأمريكان.

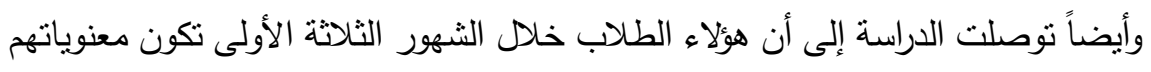
منخفضة، إلا أنها تتغير بعض الثيء مع مرور الوقت نتيجة بداية تكيفهم مع البيئة الجديدة المحبطة بهم. ع ـ دراسـة "ليفنكسـتن Livingston" ( • 9 1 ): قد تتاولت هذه الدراسـة مشـكلات طلبة ما

$$
\text { وراء البحار الذين تلقوا علومهم فى جامعات بريطانيا. }
$$

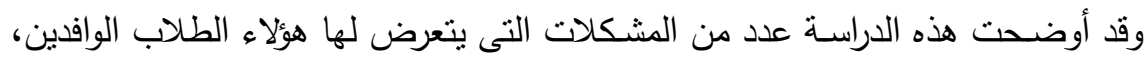

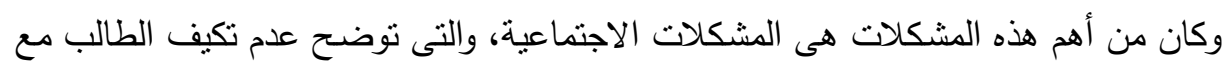

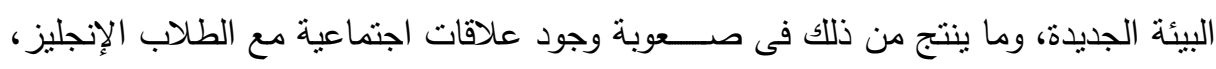

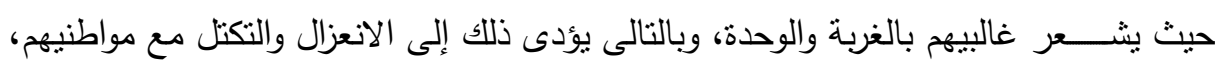

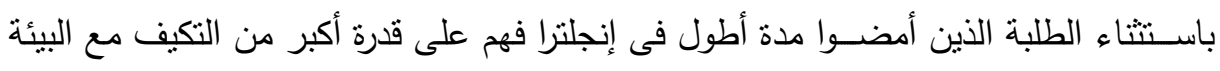

$$
\text { الجديدة، وإيجاد علاقات اجتماعية مع الآخرين. }
$$

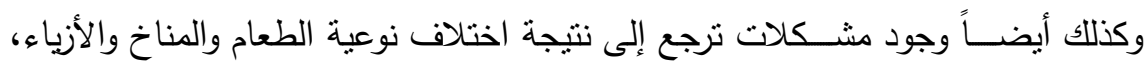
بالإضافة أيضاً إلى شعورهم ببعض التميز العنصرى، مما بؤدى إلى زيادة عزلتهم ووجود أندية خاصة بهم فقط. 
ه. دراسة "سين Sen" (9 9 1 ): وقد تتاولت هذه الدراسة مشكلات الطالبات بالجامعة ويقمن

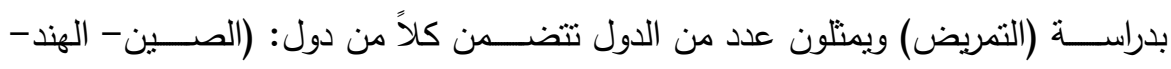

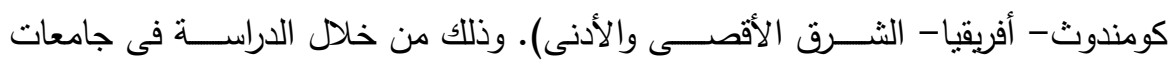
إنجلترا.

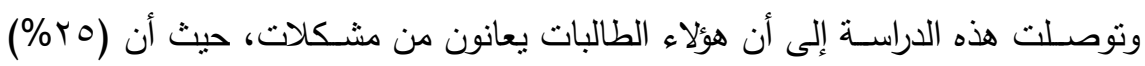

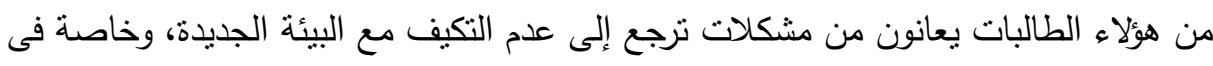
اختلاف طبيعة المناخ عن الأماكن التى أنوا منها، وكذلك أيضاً اختلاف نوعية الطعاد الطعام.

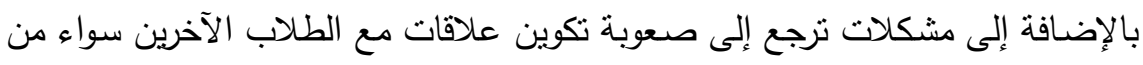

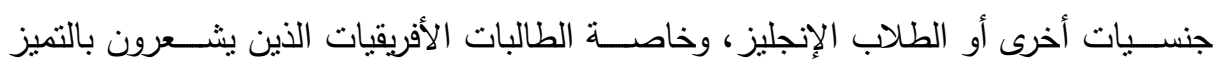
العنصرى فى المحلات العامة، أو عند محاولة للحصول على سكن.

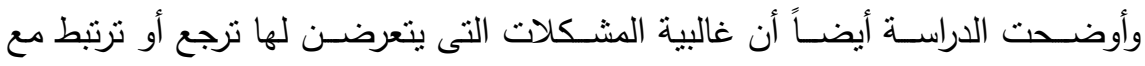

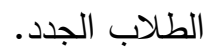

واســـتخدمت الباحثة للوصـــــل إلى هذه النتائج عدد من الأدوات منل : (أداتى المقابلة والاستفتاء- وكذلك اختبار للغة الإنجليزية يطبق على هؤلاء الطالبات).

\section{هناهمبر الدواسمة}

المفهوم هو: لفظ عام يعبر عن مجموعة متجانسـة من الأشياء وهو عبارة عن تجريد للواقع

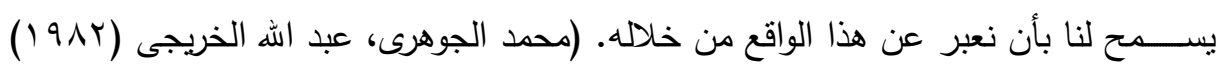
ص ص م. (1) •. مفهوم الوإفين: مصــدر كلمة الوافد هو الفعل وفد وهى تعنى القدوم من مكان آخر غير

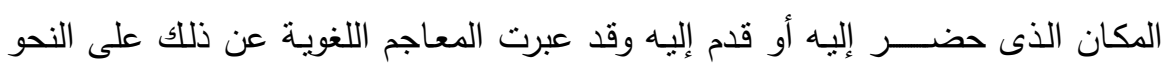

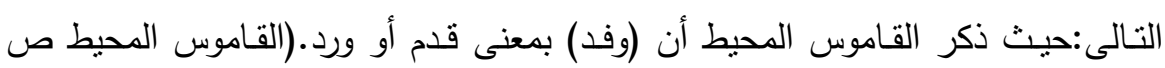


كما ذكر المنجد (وفد) وفد يفد وفداً أو وفوداً والوفود جمع الوافد وهم أقوم يجتمعون فيردون

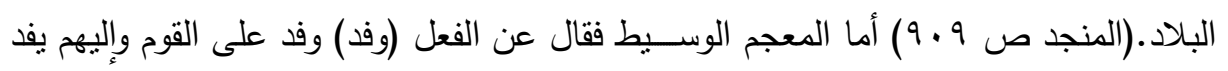

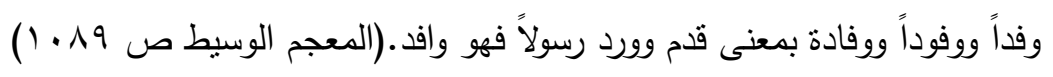

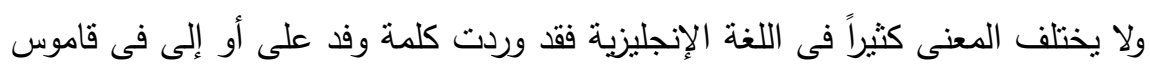

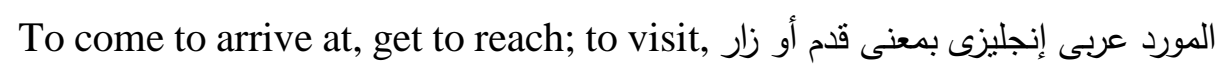
pay a visit to

وفد: موفدون، قوم وافدون delegation, deputation (المورد عربى إنجليزى ص • • ب ا)

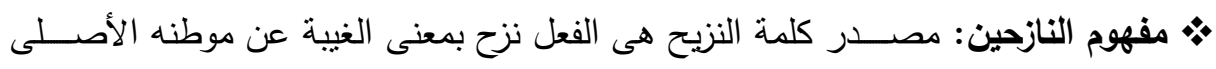

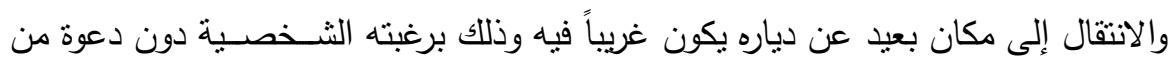

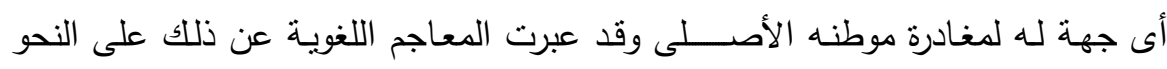

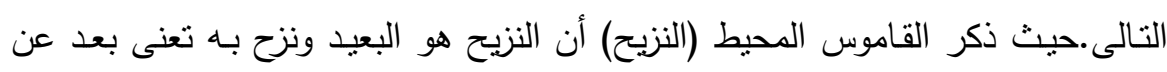
دياره غيبة بعيدة.(القاموس المحيط ص rاسب) كما ذكر المنجد (النزيح) بمعنى البعيد.

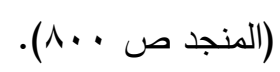

أما المعجم الوســيط فقد قال عن (النزيح). نزح نزحاً ونزوحاً أى بعد، وانتزح أى ابتعد

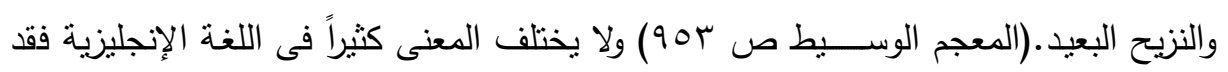

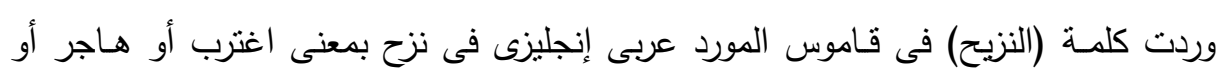
رحل.

To emigrate, expatriate, leave or be far away from one's home or country; to depart, decamp, leave, go away, move away, to immigrate (to), to migrate.

$$
\text { (المورد عربى إنجليزى ص المبعد } 170
$$

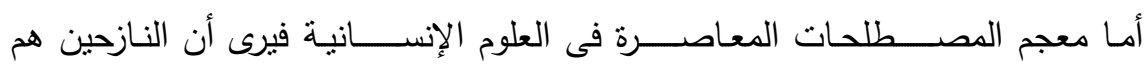

Displaced Persons

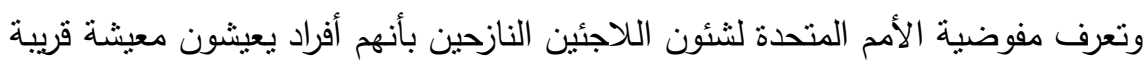

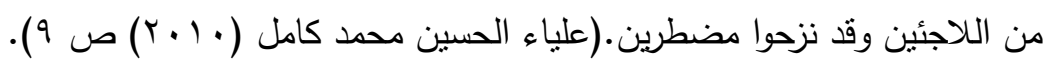


•. مفهوم الموروث الثقافي: التراث الثقافي هو مصطلح شامل وواسع وهو قد يعرف على أنه الموروث غير المادي والخبرات التاريخية والمؤسـســية الســابقة، وقد تعود للتقاليد الترانية

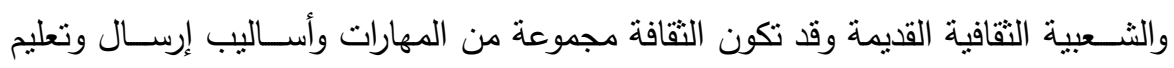

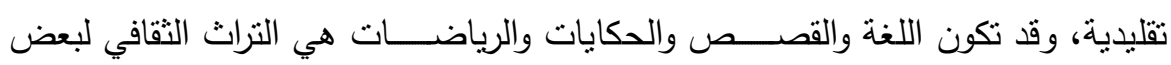

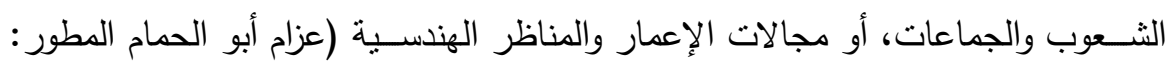

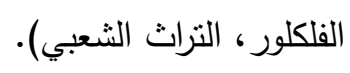

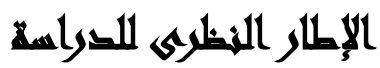

ترتكز هذه الدراسة على الإتجاه البنائى الوظيفى، الذى يعد من أهم مناهج البحث فى الهى

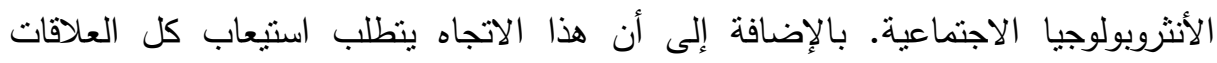
الاجتماعية المكونة للبناء الاجتماعى المستمر عبر الزمن، هذه الاستمرارية تتسم بالديناميكية.

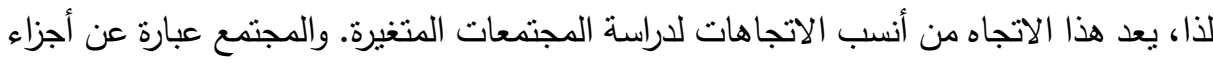
هذه الأجزاء ليست منفصلة عن بعضها فهى فى النهاية تعتبر وحدة متماسكة، لوجود تفاعل

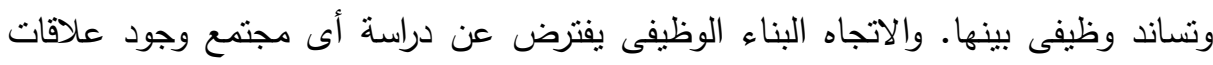

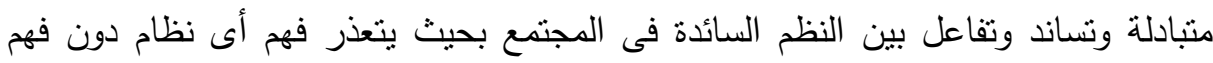

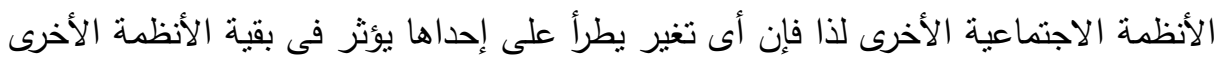

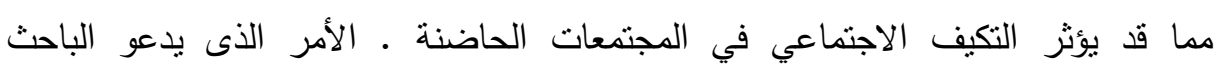

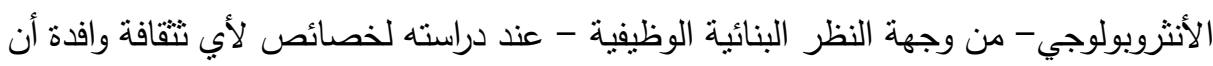

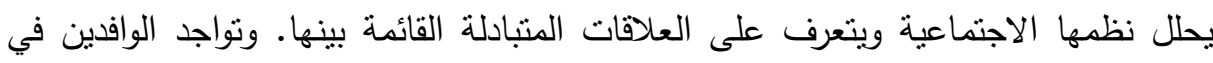

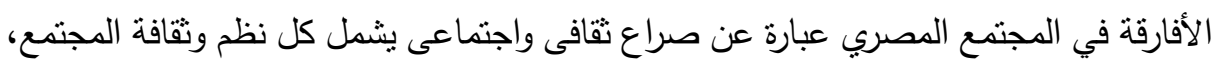

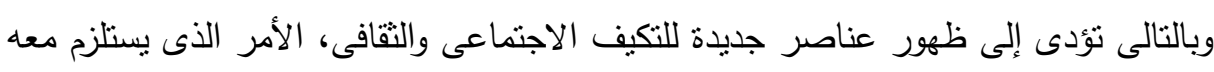
إحداث تغيرات عميقة وهامة فى ميكانيزمات التكيف لدي الوافدين. 
فتواجد الوافدين الذى يهدف إلى تحقيق أهداف تعليمية واقتصادية فى الدقام الأول كثيراً ما

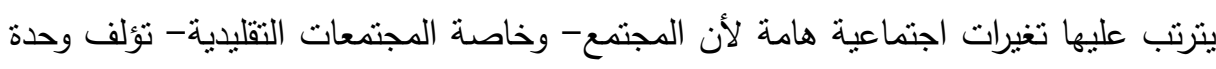

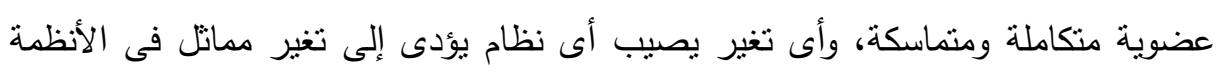

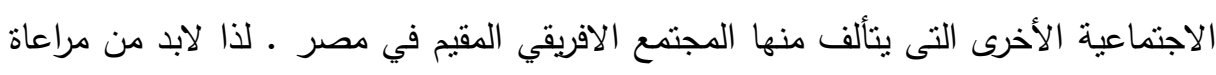

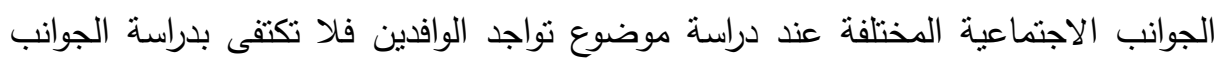
الثقافية والتراث الحكائي فقط بل ندرس أيضاً كل نظم وثقافة المجتمع، لكى نتجنب الأخطاء

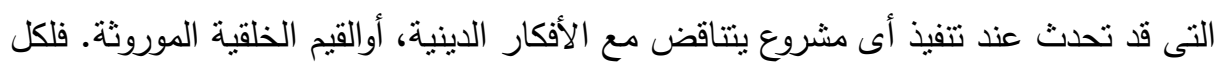

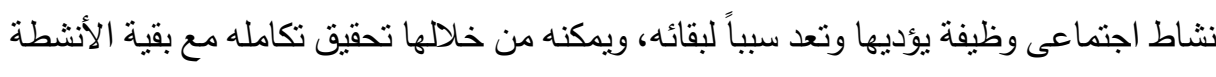

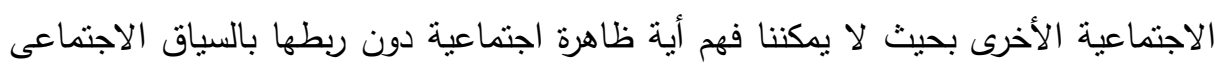

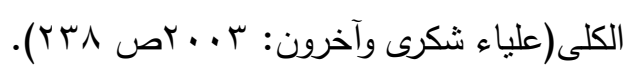

نظرية الأنساق الاجتماعية: حيث يثير مفهوم النسق إلى العناصر بين أجزاء تكون كل

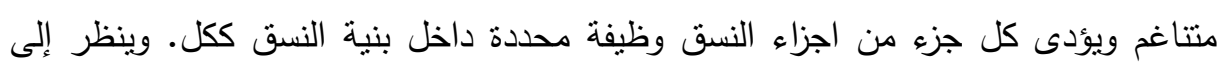
المجتمع بوصفه نسق عام يتكون من أنساق فرعية أو نظم فرعية، كالنظام الاقتصادى والنظام

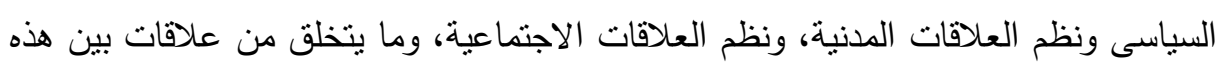

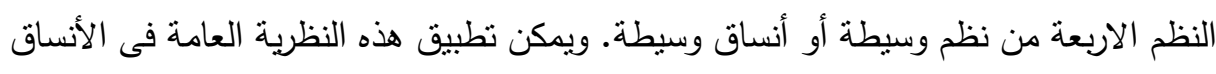

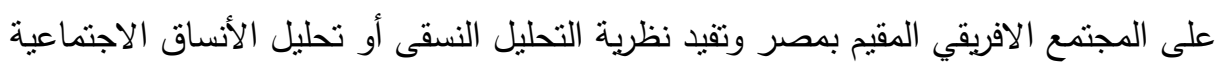

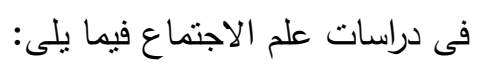
• التعرف على الطريقة التى يتكامل بها المجتمع الأفريقي داخلياً وخارجياً.

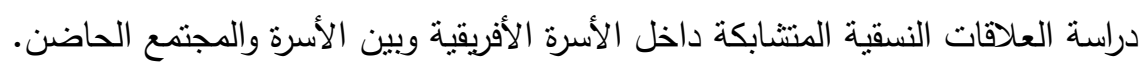

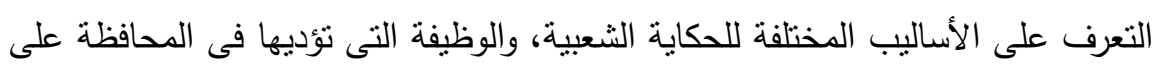
النمط الثقافى السائد. التعرف على النسق الإقليمى الذى يقع فيه المجتمع الإفريقي.

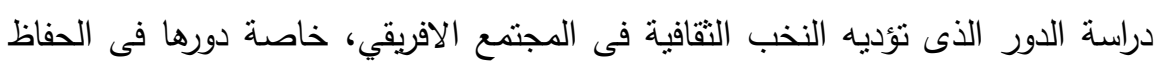

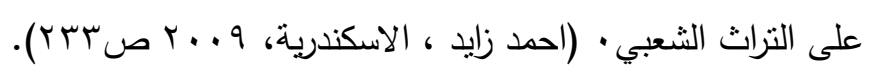


كما اعتمدت على نظرية استراتيجيات الهوية "لكارمل كاميليري"، بما إن هوية الفرد هي

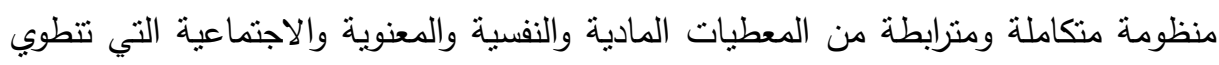

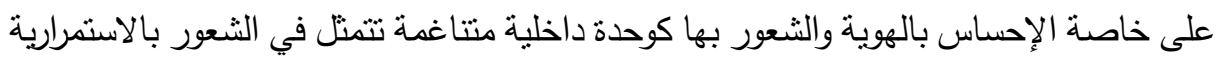

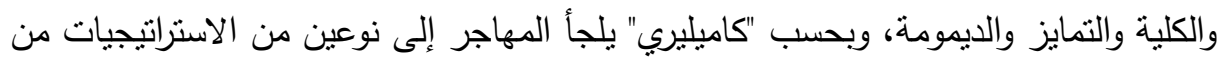

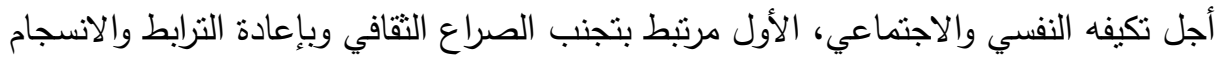

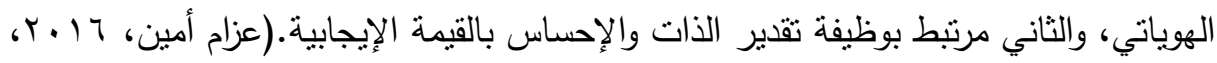

\section{الإجباءايت المنهجية}

استخدم الباحثون المنهج العلمى من خلال الآتى: أ- دراسة استطلاعية لمجتمع الدراسة: وهى خطوة أولية ضرورية لمعرفة أثر الموروث الثقافي الثعبي على إحداث التكيف في المجتمع الحاضن بغرض استكثاف الواقع من خلال

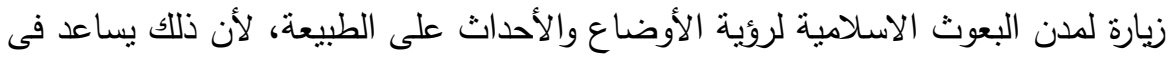
زيادة ألفة الباحث بالمبحوثين والأشخاص الموجودين والمحيطين ساعد فى وضع تصور

$$
\text { مبئى من الميدان. }
$$

ب- المسح الاجتماعى للعينة: يهدف المسح الاجتماعى إلى الحصول على صورة ديناميكية متكاملة لإطار مجتمع معين، مما يستفاد به فى معرفة الاثار المتبادلة بين الوافدين

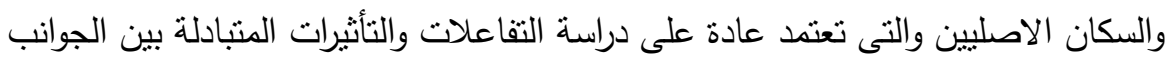
الاجتماعية والثقافية معا، كما أن المسح الاجتماعى بطريقة العينة يخدم الدراسات الوصنية درانه لأنه يهدف إلى وصف الواقع وتحليله مما يساعد على التتبؤ وأنه يعتمد على الاتصال

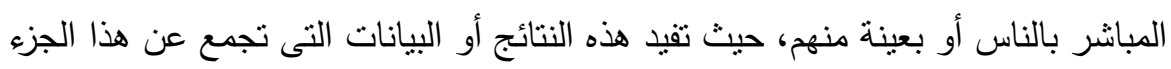

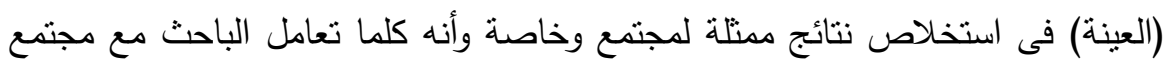
كبير الحجم كان من الأنسب استخدام المسح الاجتماعى للعينة حيث من الصعب إجراء 
مسح شامل لمجتمع البحث نظرا لكثرة التكاليف والحاجة إلى مزيد من الوقت (عبد الباسط

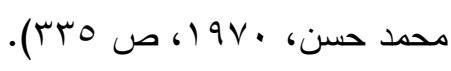

• نوع الدراسةة: نوع الدراسة وصفية حيث إن الدراسة الحالية تحاول معرفة اثر نواجد الوافدين

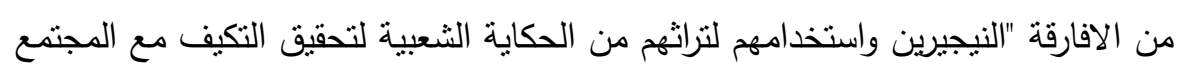
الحاضن لذلك فقد وجد الباحث أن الإسلوب الوصفى هو الأفضل في الدراسة.

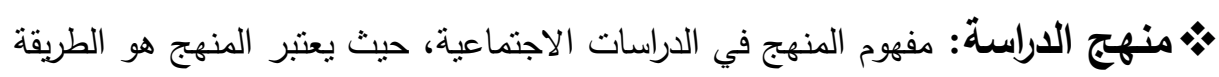
التي يتبعها الباحث في دراسته للمشكلة أو الظاهرة لاكتثاف الحقيقة ولإجابة على الأسئلة

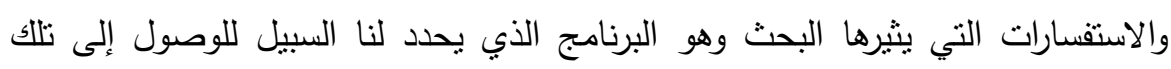

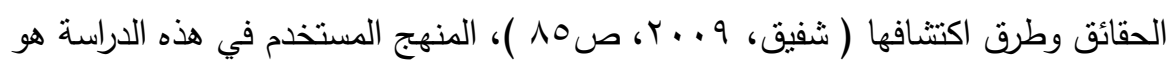
المنهج الانثرويولوجي والتعريف العلمي له هو منهج شامل لدراسة الإنسان ولا يكتفي بدراسة

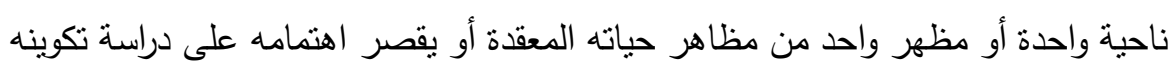

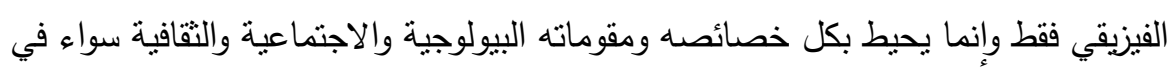

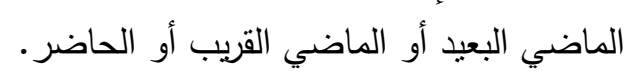
وأما تعريفه في الدراسات الاجتماعية، فهو جزء من المنهج الكيفي ويعتمد على المعايثة

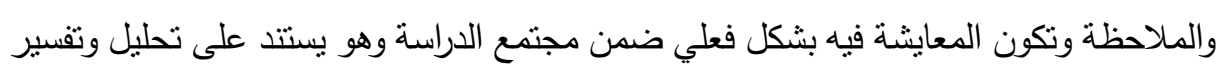
الظاهرة أو المشكلة موضع الدراسة، وكذلك هو دراسة السلوك الذي يتخذ نظم اجتماعية كالعائلة

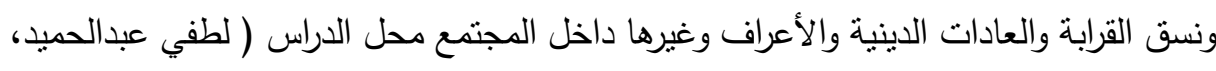

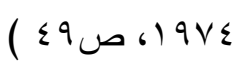

وتعريفه في علم الإنسان، هو وصف الخصائص الإنسانية البيولوجية والثقافية للجنس البشري

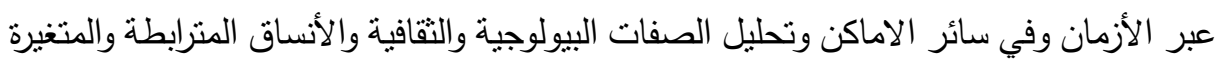
وذللك عن طريق نماذج ومقاييس ومناهج منطورة ووصف وتحليل النظم الاجتماعية

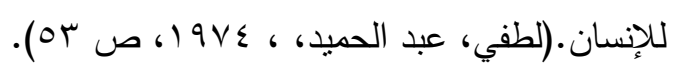




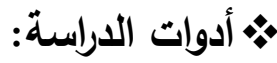

$$
\begin{aligned}
& \text { 1-الاطلاع على الإحصاءات والوثائق. } \\
& \text { r- دراسة الحالة. } \\
& \text { r- الإخباريين. }
\end{aligned}
$$

• دراسة الحالة: هى أداة من أدوات القياس وجمع البيانات للبحوث المتداولة، ويقوم من خلالها باحث أو عدد من الباحثين بطرح أسئلة تتعلق بالقيم والاتجاهات أو الأراء، وتتميز

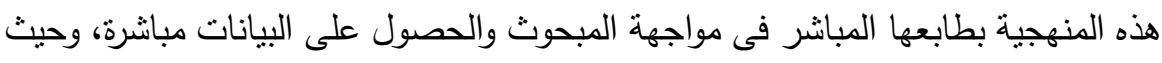
يقوم الباحث بتوجيه الأسئلة الثفهية واستيفاء الإجابات مباشرة، وتسهح للباحث بالحصول

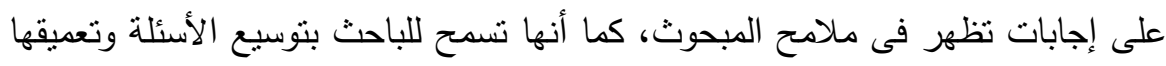

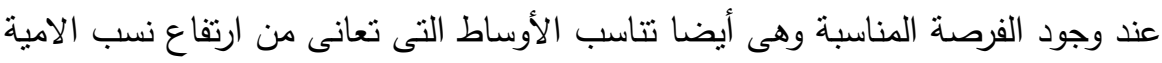

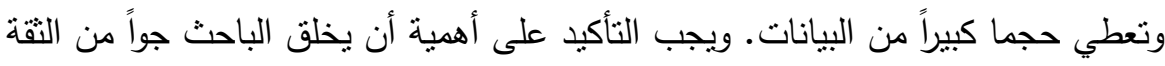
والعلاقة الطيبة بينه وبين المبحوث لينتج عن ذلك شعور المبحوث بالارتياح والاطمئنان

$$
\text { ويتعامل مع البيانات بجدية. }
$$

\section{ثروط اختيار العينة:}

(1) أن تكون أفراد العينة من جنسية نيجيريا ، بمدن البعوث الاسلامية.

$$
\text { أن تكون النسبة المختاره للعينة ممنلة لمجتمع الدراسة. }
$$

ان تكون العينة من الافراد ذوي الخلفية التراثية نسبة التعليه.

ثميفية اختيار العينة: عن طريق الإخبارين وبالاستعانة بالأخصائيين الإجتماعين العاملين

$$
\text { بمجم العينة: بمدالبعوث الإسلامية. }
$$

عينة الدراسة تمثلت في (Y) واحد وعشرون حالة، من الوافدين من الجنسية النيجيرية حيث أجريت المقابلات المتعقة مع تلاك الحالات للنأكد من بعض البيانات، وتدعيماً لعمق الدراسة 
طبق الباحث طريقة دراسة الحالة، إذ اختيرت واحد وعشرون حالة لدراستهم بشكل مركز في

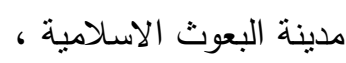

•• صدق أدوات الدراسة: حيث استخدم الباحثون الصدق الظاهري وذلك بعرض استمارات دليل

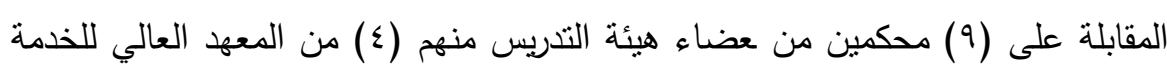

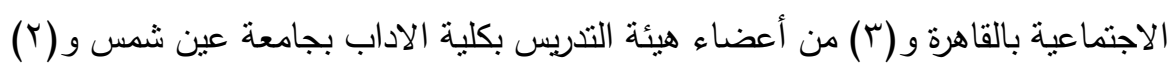

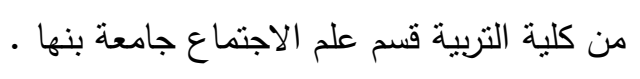

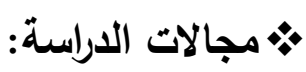

المجال البشرى: يتكون من عدد من الأفراد ( (Y) واحد وعشرون حالة، من الوافدين من الجنسية النيجيرية. المجال الجغرافي: ويقصد به النطاق المكاني لإجراء الدراسة وهو بالتحديد المنطقة البيئية التي

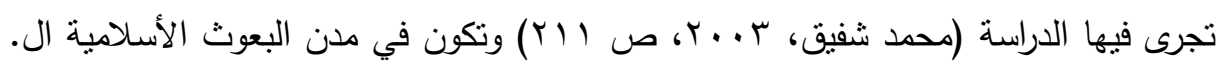

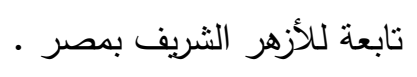

المجال الزمني: ذلك الوقت الذي يستغرق فيه إعداد البحث بأكمله مع تخصيص فترة زمنية

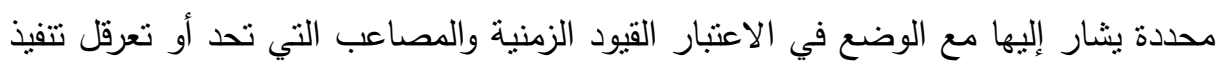

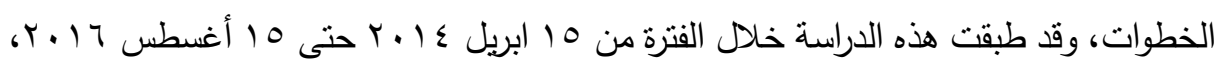

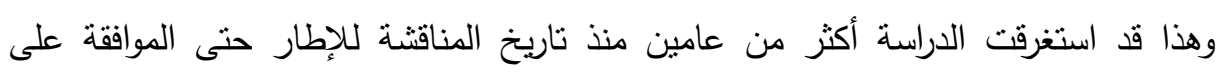

المناقثنة.

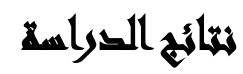

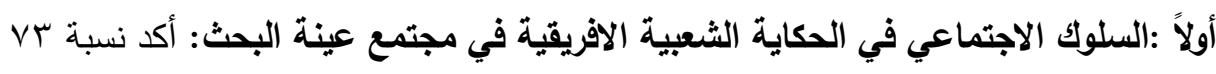

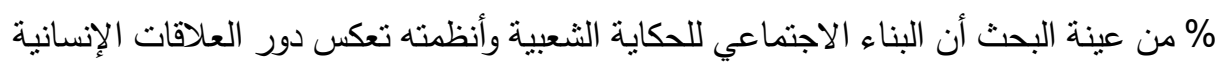

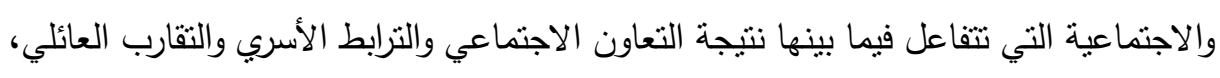

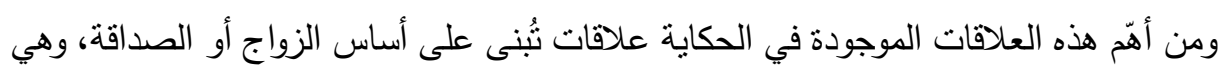

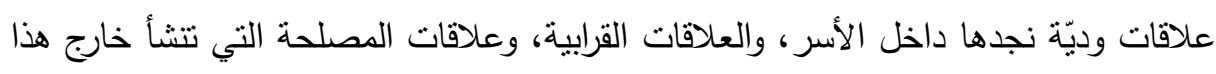
النسيج تتمثل في العلاقات الاقتصادية والسياسية. 
أكد نسبه 7^\% من عينة البحث أهّم السلوكات التي ترتبط بالحياة الاجتماعية والأسرية كالزواج والعلاقات الأسرية والقرابية؛ فمن الواضح أنّ الزواج في الحكاية الثعبية هو من أهّم

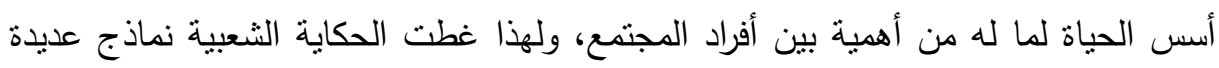
للزواج كالزواج الحر أو الاختباري وما نجم عنه من اضطرابات أسرية في حكاية "الاثياء

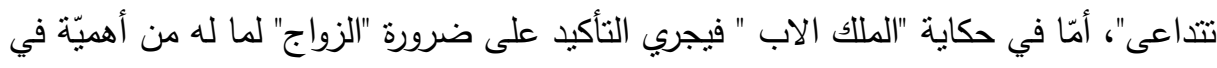
الحياة الإنسانية.

أنشار ع ؟\% من العينة أن الحكاية الثعبية النيجيرية تظهر بجلاء أنّ النسق القرابي لا ينتهي

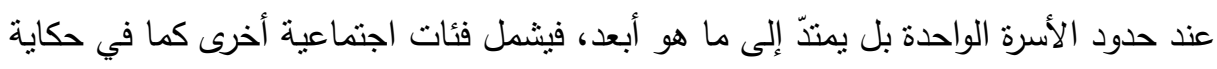

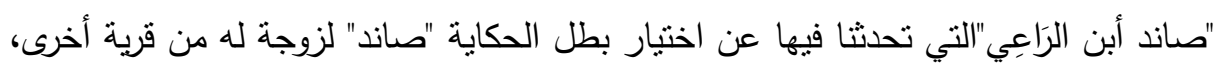
مخالفا بذلك تقاليد عشيرته المتعارف عليها. قد تبين من خلال المعايشة الميدانية أن غالبية الأفارقة في مصر يعملون بدانهان بدون تصاريح

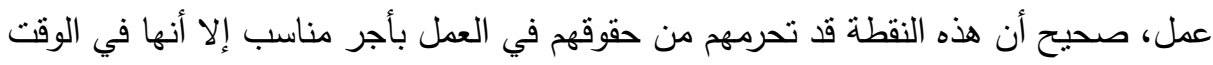

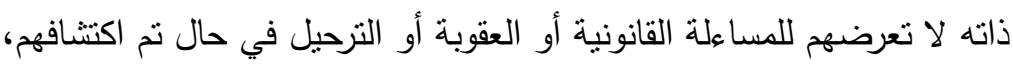
أما عن عينة الدراسة تمثلت في (Y) واحد وعشرون حالة، حيث أجريت المقابلات المتعققة مع تلك الحالات للتأكد من بعض البيانات، وتدعيماً لعمق الدراسة طبق الباحث طريقة دراسة

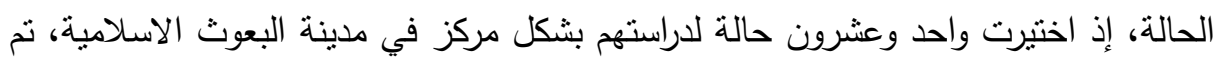

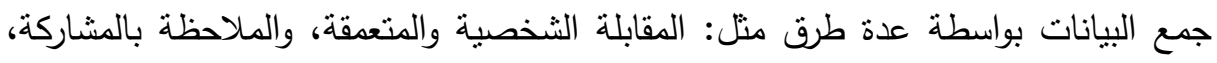
وصممت أداة بحث هي دليل العمل الميداني واثنتلت على (9) موضوعات وسؤات والت منها أسئلة

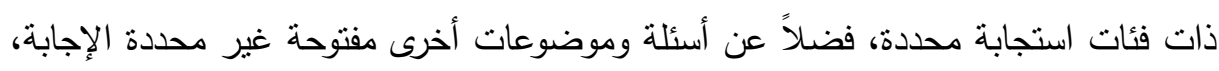

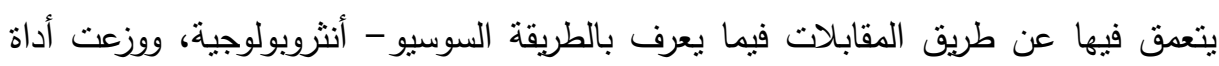
البحث على جميع الحالات. 
جدول (1 ): يوضح البيانات الأساسية لعينة الدراسة

\begin{tabular}{|c|c|c|}
\hline النسبة المئوية\%\% & الحالة & متغير الدراسة \\
\hline $\begin{array}{l}\% \leq \wedge \\
\% \circ r\end{array}$ & عنزوجون & الحالة الاجتماعية للعينة \\
\hline 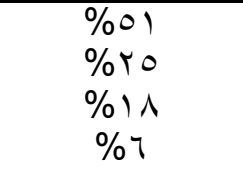 & 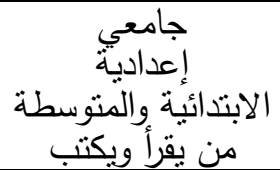 & المستوى التعليمي للعينة \\
\hline $\begin{array}{l}\text { \%rl } \\
\% r q\end{array}$ & الحالة ضتوسطةة & المستوى الاقتصادي للعينة \\
\hline $\begin{array}{l}\% 1 Y \\
\% 1 \\
\% 0 \\
\% 1 \\
\% 17 \\
\% 0\end{array}$ & 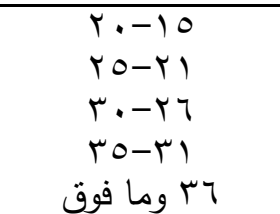 & 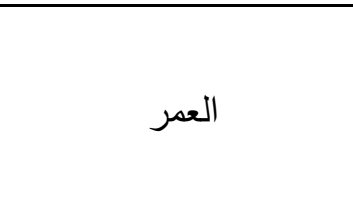 \\
\hline
\end{tabular}

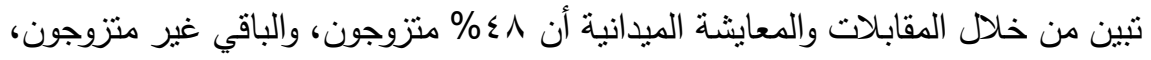
والقليل منهم مطلقون بنسبة ب\%، وأن العازبون لا يفضلون العودة إلى وطنهم بل ينتظرون

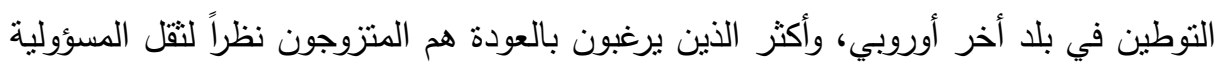

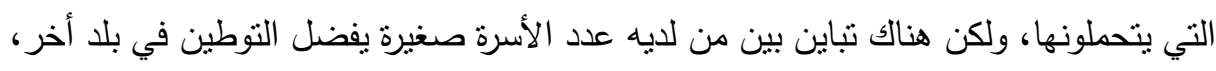

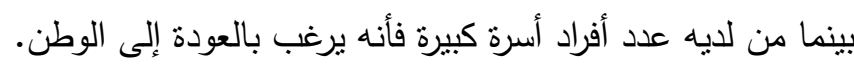

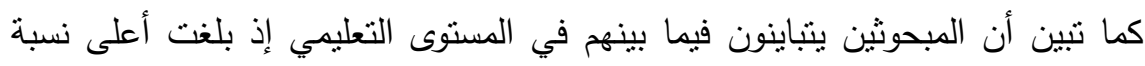

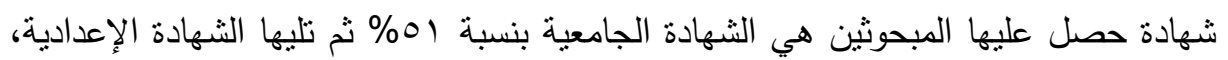

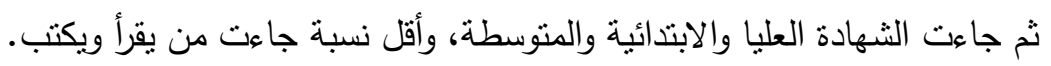

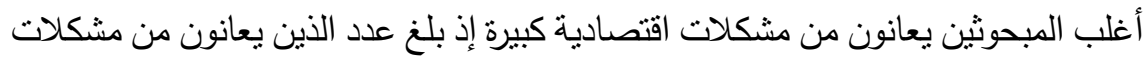
أقتصادية ضعيفة وصلت إلى آ7\%، ثم تلي حالتهم المتوسطة، كما أنهم يعانون من عدم وجود فرص عمل تكفل لهم دخل منتظم. 
ثانياً: وصف وتحليل مشكلات المهاجرين الأفارقة ن في المجتمع المصري: تُعد عملية عرض

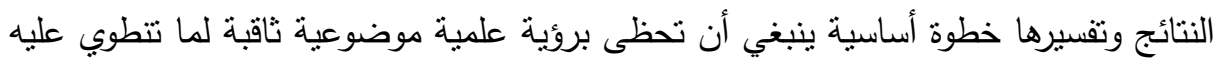
من عملية نقل لحقائق الميدان إلى نطاق التحليل والتفسير العلمي، وإن إحاطة تحليل البيانات بلدئل بالحياد والموضوعية مسألة غاية الأهمية من أجل تحقيق أهداف البحث.

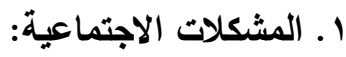

جدول (r): لتوضيح المشكلات الاجتماعية للوافدين الافارقة في مدن البعوث الاسلامية

\begin{tabular}{|c|c|}
\hline النسبة المئوية\%\% & متغير الاراسة \\
\hline$\%$ & العزلة الاجتماعية \\
\hline$\% \backslash Y$ & القلق على زواج البنات والأبناء \\
\hline$\%) \varepsilon$ & وقت الفراغ \\
\hline$\% \vee$ & الصراعات بين الآباء والأبناء \\
\hline$\% 9$ & صعوبة الاختلاط بسبب اللهجة \\
\hline
\end{tabular}

تبين من الجدول السابق أن الوافدين الافارقة يواجهون العديد من المشكلات الاجتماعية في البلا المضيف "مصر"، ويمكن حصرها في الأتي: - ظهور الصراعات بين الأبناء والإباء في محيط الأسرة بسبب اختلاف أسلوب الحياة بين المجتمع الأصلي والمجتمع الحاضن، كما أن هذا الصراع له أسبابه الأخرى منها تقدم وسائل الأل الاتصال وتكيف الأبناء مع حياة جديدة قد خلق نوع من الصراع بين الآباء والأبناء.

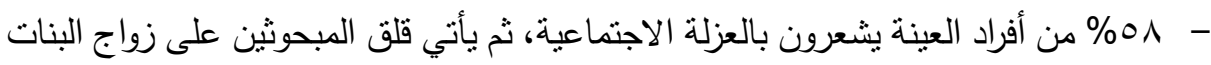

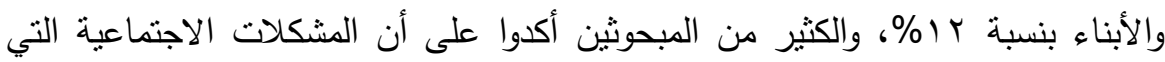

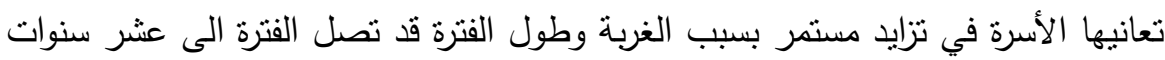

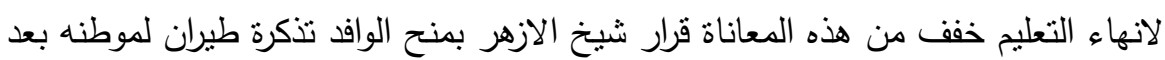
الانتهاء من كل مرحلة دراسية .

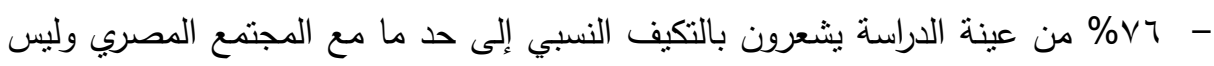

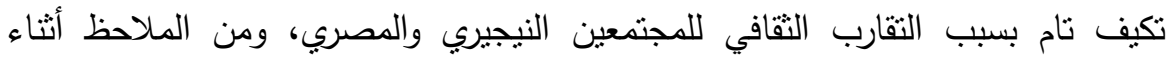

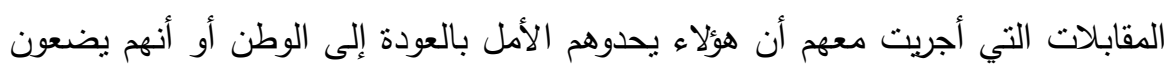


في حسابهم الانتقال إلى بلد ثالث، فضلاً عن ذلك بعضهم يخرج من بلده لأول مرة ولم يتعود على وجوده خارج نسقه الثقافي الذي نشأ فيه.

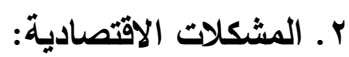

\begin{tabular}{|c|c|}
\hline النسبة المئويةه\% & متغير الدراسة \\
\hline$\%$ & يعانون من مشكلات الفقر والبطالة والحرمان \\
\hline$\%$ \%. & القلق من نفاذ مدخرات الأسرة \\
\hline$\% 10$ & صعوبات نحول دون فتح مشاربح استثمارية \\
\hline
\end{tabular}

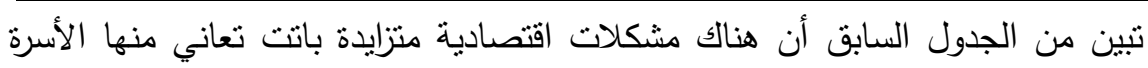

المهاجرة، إذ مثلت مشكلات: البطالة والفقر والحرمان، نسبة كبيرة في الواقع الاجتماعي؛ إذ رأى دأى عدد من المبحوثين يصل عددهم إلى 7\% \% أن المهاجرون يعانون من مشكلات الفقر والبطالة

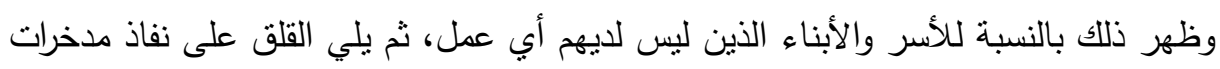

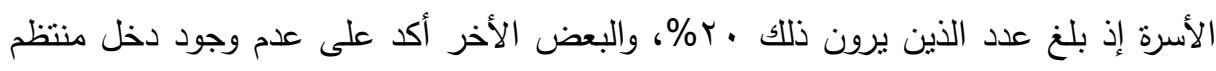

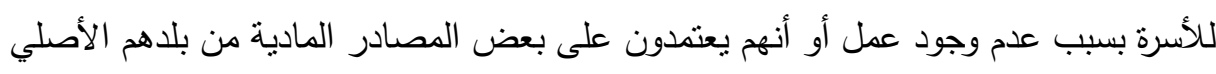

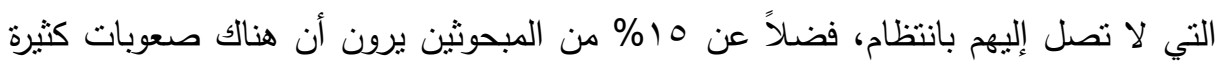

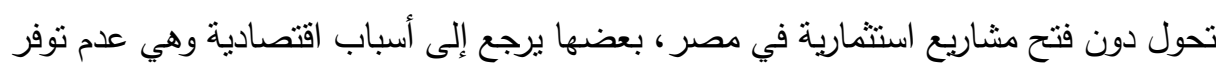

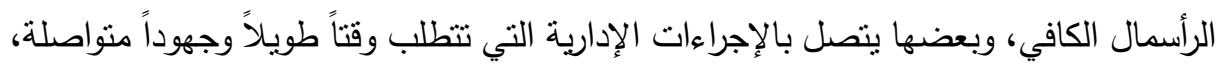
كما أن عملية فتح مشاريع تخضع لشروط طويلة.

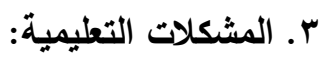
جدول (؛ ): لتوضيح المشكلات التعليمية للافارقة بمصر

\begin{tabular}{|c|c|}
\hline النسبة المئوية\%\% & متغير الاراسة \\
\hline \%rr & صعوبة المناهج \\
\hline$\% \vee$. & التكاليف عالية في المدارسّ من الألية لعدم في حال عدم وجود \\
\hline$\% V$ & اختلاف اللهجة تمنل عائق للتعليم بالنسبة للأطفال \\
\hline
\end{tabular}

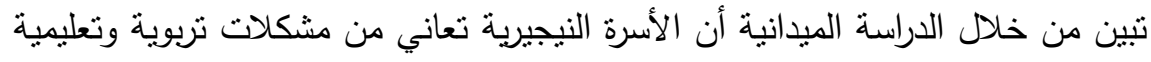

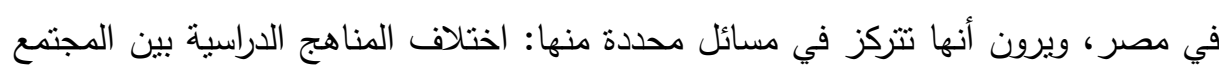
الأصلي والمجتمع الحاضن "مصر" وذلك بسبب كثير من الصعوبات لتعلم الأطفال والأبناء 154

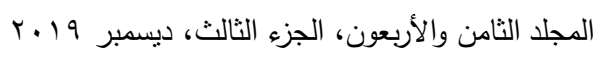


وذللك بنسبة rr\% من المبحوثين، والبعض الأخر لا يرون صعوبة كبيرة في المناهج، يلي

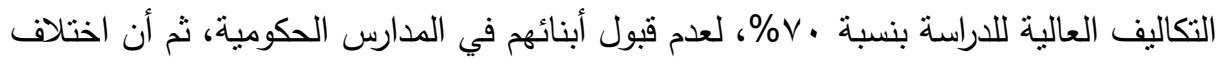
اللهجة تمنل مشكلة تعليمية بالنسبة للأطفال بنسبة \\%، ولاحظ الباحث من خلال العمل الميداني

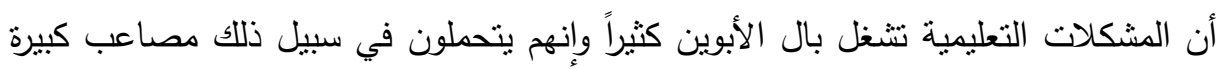

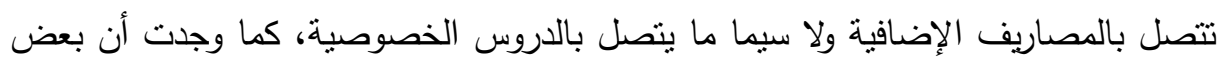

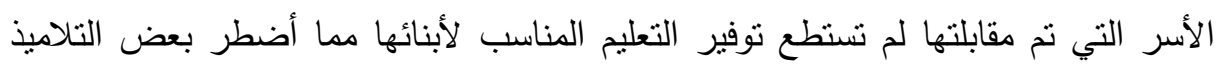

وكثير من الثباب إلى الانقطاع عن الدراسة وعدم النسجيل فيها.

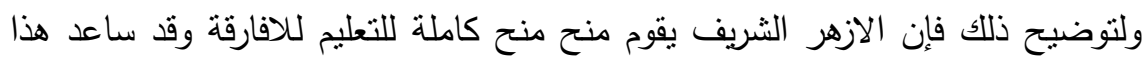

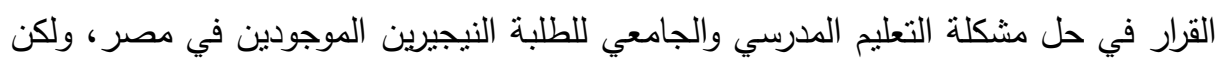

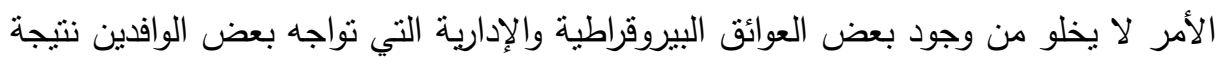
عدم امتلاكهم الأوراق الكاملة.

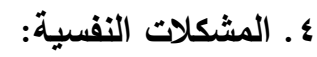
جدول (0): يوضح المشكلات النفسية للافارقة النيجيريين

\begin{tabular}{|c|c|}
\hline النسبة المئويةة\%\% & متغير الدراسة \\
\hline$\% \wedge \Sigma$ & الخوف والقلق من المستقبل \\
\hline$\% 4$ & الخوف من مستقبل عائلاتهم في البلد الأصلى "نيجيريا" \\
\hline$\% \varepsilon$ & ازدياد القلق والضغوط النفسية \\
\hline$\% r$ & الاغتراب والغربة \\
\hline$\overline{\% r}$ & الحنين إلى الوطن \\
\hline$\% 1$ & عدم القدرة على التكيف السريع في المجتمع المصري \\
\hline
\end{tabular}

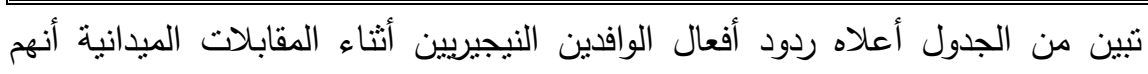

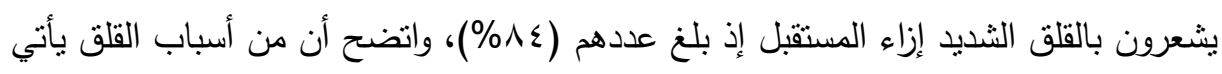

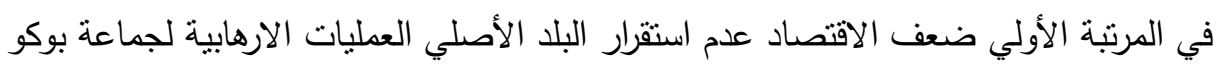

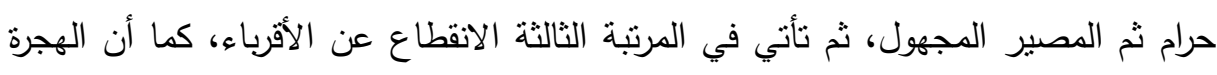

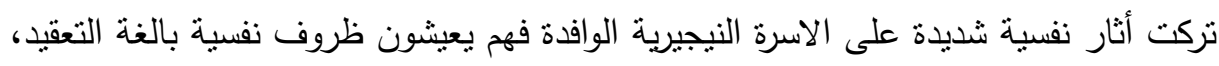
حيث تتوزع معاناتهم على النحو التالي: الاكتئاب والضياع، ثم فقدان الأصدقاء، فالعزلة التي لتئي 
يشعر بها البعض والملل والقلق المستمر على مستقبلهم وطول فترة البقاء في المهر وغياب روية واضحة عن المستقبل

ولذلك يمكن القول من خلال سرد ما سبق من مشكلات أن الوافدون يعانون من مشكلات

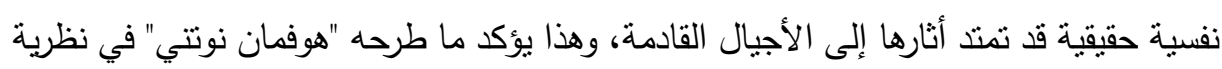

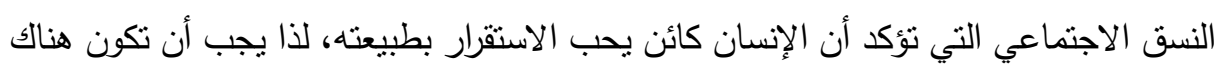

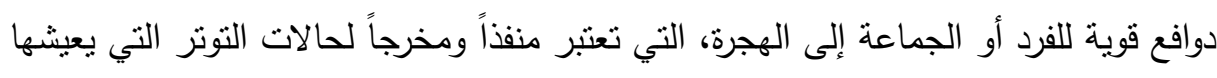

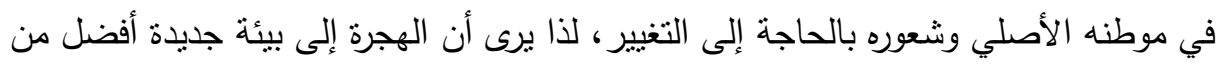

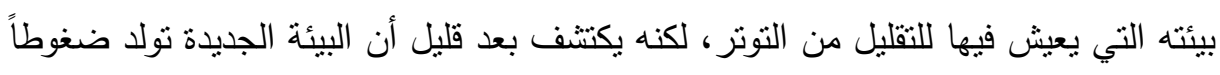
وصراعات قد تؤدي إلى خلق حالة من التوتر النفسي وعدم التوازن النفسي والاجنماعي (ذكري لنئي

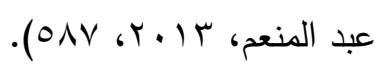
- التشابه بين الموروث النقافي النيجيري والمصري. - أكد بr\% من عينة البحث عل ى التشابه الكبير بين الحكاية الثعبية النيجيرية بأنواعها المختلفة مع ما اسنطاعوا التواصل معه من الحكاية الثعبية المصرية.

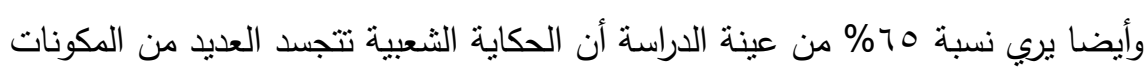

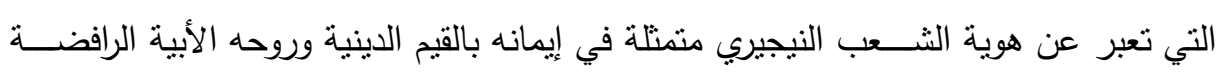

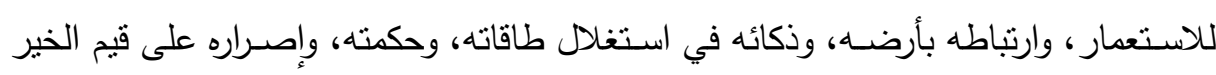

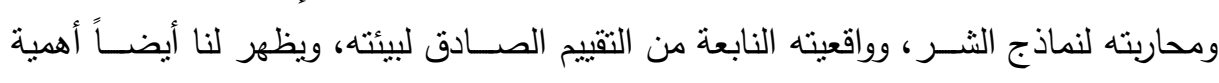

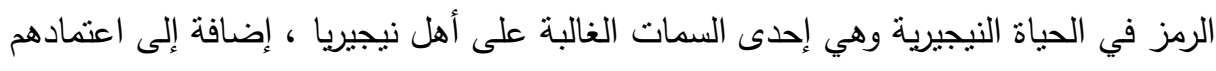

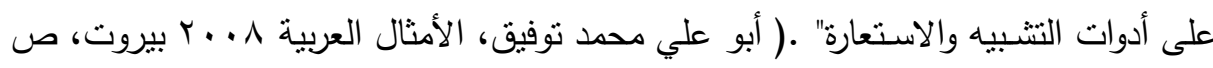

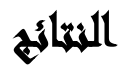

- غياب خطة واضـــة للمصــالح والأهداف المبتغاة من العملية التعليمية للطلاب الأجانب والأفارقة منهم بصفة خاصة.

- - غياب التسيق بين الأجهزة والمؤسسات المسئولة عن العلاقات الثقافية مع أفريقيا. - - غلبة الاعتبارات السياسية الآنية فى رسم وتتفيذ السياسات. 
- عدم الحرص على متابعة السياسات المطبقة ودعم الروابط العقلية التى تم إيجادها.

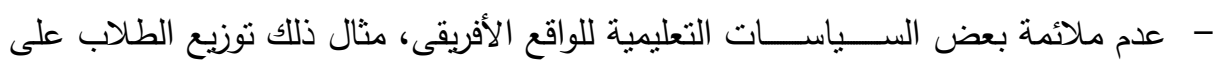
الكليات العملية والكليات النظرية (الثرعية).

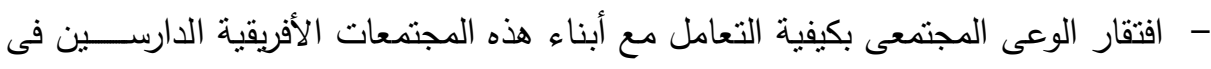
مصر على نحو ينعكس سلبياً على خبراتهم المكتبة ومشاعرهم تجاه مصر وسياستها.

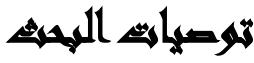

ا. عدم التركيز كلية على الجانب الامني فقط في دراسة قضية تواجد الوافدين خاصة الافارقة

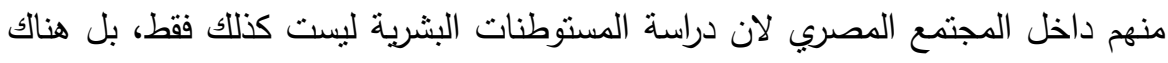

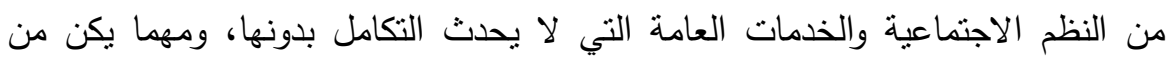
صعوبات فيجب على المرتمين بشأن تواجدين الافارقة بمصر اعتبار تكيف الوافدين الإفارقة في المجتمع المصري هي من القوى الناعمة في مسألة الامن القومي المصري والبعد الإفريقي

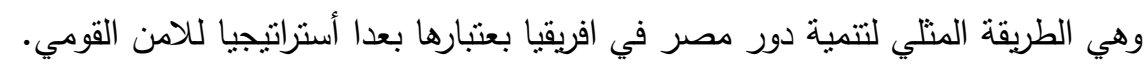

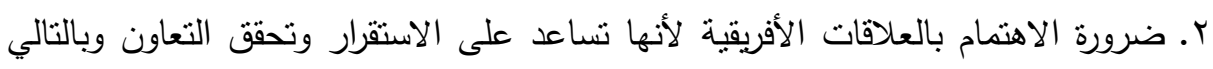

$$
\text { التكيف مع البيئة الجديدة. }
$$

r. الاهتمام بدعم الخدمات الموجودة بمجتمع الدراسة وأهمها التعليم الجيد والبرامج التنقيفية .

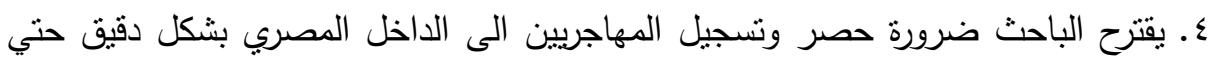
نتجنب تكوين جيوب سواء اجرامية او تؤثر سلبا على العادات والقيم الاجتماعية بالمنطقة

$$
\text { التي تستقبل نلك الهجرات. }
$$

ه. يقترح الباحث وضع ضوابط لعملية الهجرة من الدول المجاورة الى داخل المجتمع المصري

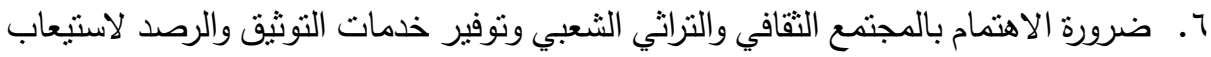

ايه مظاهر تراثنة قد لا تلائم العادات والاعراف المصرية قدتفد الى المجتمع المصري.

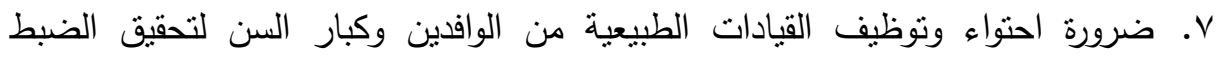
المجتمي للوافدين في ظل نقص المعلومات التي يحيط باعداد المهاجريين وانشطتهم 
^. الإسراع في إيجاد الأرضية الأمنية الملائمة لعودة هؤلاء المهاجرين إلى مناطقهم الأصلية

$$
\text { ومساكنهم. }
$$

9. تشجيع المبادرات الخاصة من قطاعات المجتمع المدني للتواصل مع ثقافات وتراث المهاجرين ومحاولة التوصل إلى مششترك ثقافي يحقق التكيف المجتمعي للوافد والامان

$$
\text { النقافي والاجتماعي للمجنمع المصري. }
$$

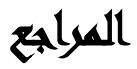

إبراهيم شعراوى: الخرافة والأسطورة فى النوبة- الهيئة المصرية للكتاب. القاهرة. عد91ا. ص vr أحمد أمين: قاموس العادات والتقاليد والتعابير المصرية. الطبعة

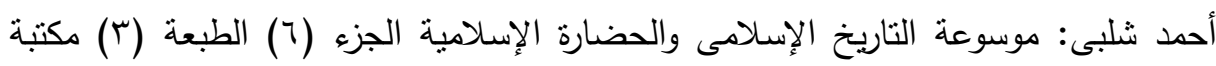
النهضة القاهرة 19V1 الإنلاهى ص 79

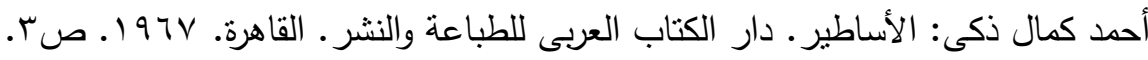
بطرس بطرس غالى: الأقلات وحقوق الإنسان فى الفقه الدولى، مجلة السياسة الدولية، العدد

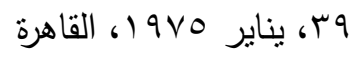

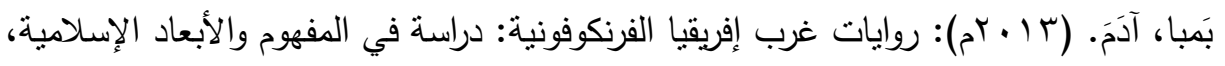

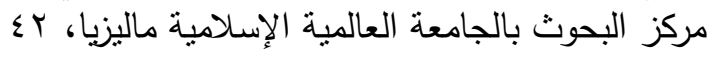

جالك شوفرييه: نظرة إلى التراث الثفهى فى أفريقيا السوداء. ترجمة نورا أمين. مجلة الفنون الفهابه الثعبية. العدد (V \& ). الهيئة المصرية العامة للكتاب. القاهرة.

VV

جودة حسنين جودة: جغرافية إفريقيا الإقليمية. الطبعة (9) الناشر منشأة المعارف بالإسكندرية.

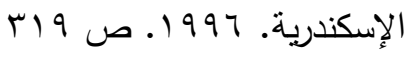

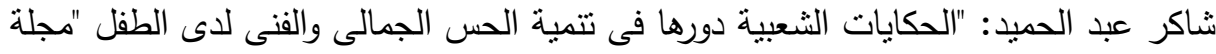

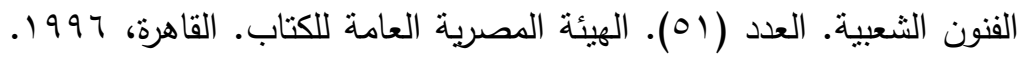

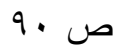

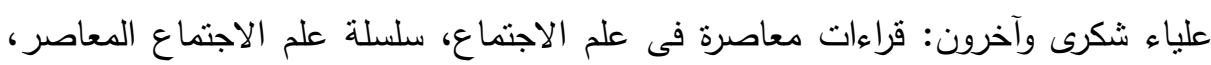

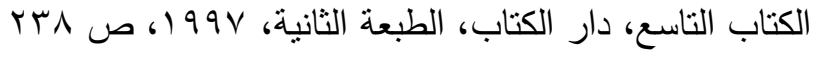

القاموس المحيط، محمد بن يعقوب الفيروز آبادي، مؤسسة الرسالة، بيروت، د. ت دادة، دادة حكي. 158

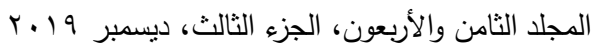




$$
\begin{aligned}
& \text { لطفي، عبد الحميد: الأنثروبولوجيا الاجتماعية، دار المعارف بمصر } 9 \text { لو } \\
& \text { مختار الصحاح، محمد بن أبي بكر بن عبد القادر الرازي، مكتبة لبنان ناشرون، بيروت، }
\end{aligned}
$$

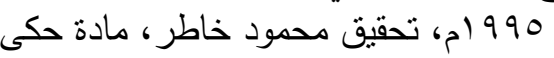

Abner Cohen, (ed), Urban Ethnicity, Tavistock Publications, London, 1974, PP. 14-16

Anderson, J.D.: "Stories of the peoples of Africa. West Africca and East Africa in the Nineteenth and Twentieth Centuries". Heinemann Educatonal Books, London- GB, 1972, P. 184.

Claude Levi- Strauss, the Raw and the Cooked, Harper and Row, New York, 1969, PP. 35-44.

Comment on Fine and Kleinman, In, American Journal of Sociology, Vol. 87, July, 1981- May, 1982, PP. 170-173.

\title{
THE CULTURAL HERITAGE AND ITS RFLATION ON SOCIAL ACCOMMODATION IN THE INCUBATOR COUNTRIES
}

\author{
Ahmed M. M. Harby ${ }^{(1)}$; Mustafa I.Awad ${ }^{(2)}$ \\ and Rhashad A.Abdel Latif ${ }^{(3)}$
}

1) Post Grad. Institute of Environmental Studies \& Research, Ain Shams University 2) Institute of Environmental Studies \& Research, Ain Shams University 2) Faculty of Social Worker, Helwan University.

\begin{abstract}
This study aims to identify the effects of the convergence of two African cultures represented in the African folk tale (Nigerian as an example); and try to uncover the type of influence and influence, and give and take between them, in what is known as the phenomenon of
\end{abstract}

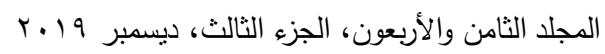


"acculturation" (Acculturation), a phenomenon that usually occurs silently and quietly; On both sides, the cultural elements of the other side ar e digested in a subconscious manner and, moreover, these are digested in a healthy manner that increases the strength of the newcomer's adaptation to their new environment. In the African-Egyptian case, the adaptation between the two cultures is a merger of cultures of the same. Origins Unlike Strkh resistance by the heritage versus globalizationWhere can you be dreaming of a folk tale? On the difference and the history of self in the kindergarten (not material) imagined and absent and inherited Stand in the face of crushing and alienation represents the study saple in (21) twenty-one cases. 